

\title{
Description of supported metal structure sensitivity by a geometric approach
}

\author{
Anthony Le Valant, Samuel Bouchet, Alexandre van Assche, Catherine \\ Especel, Florence Epron
}

\section{- To cite this version: \\ Anthony Le Valant, Samuel Bouchet, Alexandre van Assche, Catherine Especel, Florence Epron. Description of supported metal structure sensitivity by a geometric approach. Journal of Catalysis, 2021, 10.1016/j.jcat.2021.03.021 . hal-03219223}

\section{HAL Id: hal-03219223 \\ https://hal.science/hal-03219223}

Submitted on 6 May 2021

HAL is a multi-disciplinary open access archive for the deposit and dissemination of scientific research documents, whether they are published or not. The documents may come from teaching and research institutions in France or abroad, or from public or private research centers.
L'archive ouverte pluridisciplinaire HAL, est destinée au dépôt et à la diffusion de documents scientifiques de niveau recherche, publiés ou non, émanant des établissements d'enseignement et de recherche français ou étrangers, des laboratoires publics ou privés. 


\title{
Description of supported metal structure sensitivity by a geometric approach
}

Anthony Le Valant*, Samuel Bouchet, Alexandre Van Assche, Catherine Especel, Florence Epron

Institut de chimie des milieux et des matériaux de Poitiers (IC2MP), Université de Poitiers, UMR 7285 CNRS, 4, rue Michel Brunet, 86073 Poitiers cedex 9, France

* Corresponding author.

E-mail address: anthony.le.valant@univ-poitiers.fr

\begin{abstract}
A series of $\mathrm{Pt} / \mathrm{Al}_{2} \mathrm{O}_{3}$ catalysts with uniform Pt particle sizes ranging from 0.95 to $2.62 \mathrm{~nm}$ was synthesized using the refilling method to control the growing of Pt nanoparticles and evaluated in propane dehydrogenation. An effect of particle size on the initial propane activity and TOF was demonstrated, the smallest particles being the most active. A geometric model was developed to quantify the surface site concentration for any fcc metal particle size. Comparing the evolution of initial activity for propane dehydrogenation with the different surface site concentrations, it was shown that the active sites of $\mathrm{Pt} / \mathrm{Al}_{2} \mathrm{O}_{3}$ catalysts corresponded to the combination of corner and edge atoms. To get further, the model was confronted with numerous data extracted from literature demonstrating that it is an efficient tool to predict the structure-activity relationship of fcc metal catalysts and determine the exact nature of active sites for a wide range of reactions and metals.
\end{abstract}

Keywords: Platinum; Geometric model; Truncated octahedron; Controlled particle size synthesis; Size effect; Propane dehydrogenation; Surface site concentration; Structure-activity relationship; fcc metal.

\section{Introduction}

Metallic catalysts are of great importance in various fields such as synthesis chemistry, energy production but also environment processes $[1,2,3,4]$. The most common metals (supported or not) used in heterogeneous catalysis belong to groups 8 to 11 (Fe, Ru, Co, Rh, Ir, $\mathrm{Ni}, \mathrm{Pd}, \mathrm{Pt}$, $\mathrm{Cu}, \mathrm{Ag}$ and $\mathrm{Au}$ ). For decades, the complexity of unsupported metallic catalysts has motivated 
fundamental investigations with simple model catalysts. In the 1970's, the works of Somorjai [5] based on the ultrahigh vacuum techniques investigated single crystals of metal determining both the exact surface structures by low energy electron diffraction (LEED) and their compositions by Auger electron spectroscopy (AES). This experimental approach provided impactful determinations of structure-property relationships of metallic catalysts. The results of such investigations showed how catalytic reaction activities vary from one metal crystal face to another [5]. Single crystals models provide incisive information about the effects of surface structure and composition on catalysis, but they provide no information about support effects and only limited, indirect information about supported metal particle size effects (the results are limited by any assumption that variation of crystal face and density of step, edge, kink, terrace, etc. sites accounts for crystallite size effects in supported metals). Single crystals also cannot accurately represent the smallest particles (particles with diameters less than about 1 $\mathrm{nm}$ ), which may lack metallic character and may have unique structures and resemble molecules rather than two-dimensional extended solids [6].

Because of the limitations of single crystal models, researchers have worked toward simple models of supported metal catalysts.

Size and shape of the metal particles are the main characteristics which influence their electronic properties and so the catalytic activity of these supported nano-objects [7]. These specific properties are generally attributed without distinction to all surface atoms (called active sites) by opposition to bulk atoms of the particles [8]. Theoretical analyzes by Van Hardeveld and Hartog [9] on ideal geometric structures clearly showed the reliance of the fraction of the different types of crystallographic sites (corner, edge, faces) present on the surface with the size of the particles. In the case of ideal structures, the proportion of the atoms constituting the edges and the corners versus the quantity of surface atoms becomes larger as the nanocrystals become smaller. The size effects are mainly due to a not insignificant proportion of weakly coordinated sites (such as corner and edge atoms). In an ideal setting, size conditions the nature of the sites on the surface. Therefore, particle size can normally be correlated with catalytic activity.

However, reactions in heterogeneous catalysis can be split into two groups: those that are not sensitive to the size and the shape of the catalyst particles and for which each surface atom of the catalyst is supposed to be equally active; and structure sensitive reactions for which specific size and/or particular shape of metallic particles can greatly enhance the catalytic activity [10]. 
As far as structure sensitive reactions are concerned, the knowledge of the type of active sites is the key point to design an optimal catalyst for a given reaction. However, the determination of these active sites requires complex and time consuming calculations in order to predict the interaction energies between reactants and metallic surface atoms $[11,12]$. One reason of this complexity is due to the diverse types of surface metallic atoms differing in coordination number. A considerable simplification, called scaling model [13], allows a quite easily determination of this interaction energy even for complex reactants once the adsorption energy of the considered atom linked to the metal is known.

However, this methodology does not take into account the structure sensitivity and can therefore not well describe the global activity of a real catalyst. Recently, Calle-Valljo et al. $[14,15]$ have gone deeper in the scaling model by integrating the geometry of the active site, which can be simply described by the number of neighbour atoms. These general scaling models thus allow to determine the optimum composition of the catalyst and its surface structure for a given reaction. However, this methodology requires theoretical skills and tools, and thus can only be used by experts in the field.

Development of a simple and affordable methodology allowing to mimic the type(s) of active sites for a given metallic nanoparticle would be a diagnostic tool of great interest for the heterogeneous catalysis community, which would save a tremendous amount of time for the design of catalytic materials.

Depending on the molecules involved in the reaction, dehydrogenation reactions may be either sensitive or insensitive to the structure. Propane dehydrogenation (denoted PDH) on Pt-based catalysts has often been considered as a structure sensitive reaction [16], although this aspect was not really studied. In 2008, Holmen and co-workers reported for the first time a Pt particle size effect for Pt-SBA15 catalysts, those with the smaller metallic particles, around $3 \mathrm{~nm}$ diameter, being more active for propane dehydrogenation than those with larger particles of $21 \mathrm{~nm}$ diameter, with also an effect on the selectivity to propylene and on coke formation [17]. Thereafter, a more in depth study performed on a series of platinum catalysts supported on hydrotalcites with nearly monodispersed sizes, ranging from 1 to $10 \mathrm{~nm}$, clearly demonstrated, by combining kinetic analysis with density functional theory calculation and isotopic experiments, that Pt catalysts present a strong structure sensitive behavior for PDH reaction [18]. These results were very recently confirmed on a series of more classical $\mathrm{Pt} / \mathrm{Al}_{2} \mathrm{O}_{3}$ catalysts with nanoparticles ranging from atomically dispersed Pt to ca. $12 \mathrm{~nm}$ of diameter, by varying 
the Pt content from 0.05 to $5 \mathrm{wt} . \%$, and applying thermal treatment for the highest Pt content in order to sinter Pt nanoparticles [19].

In this context, the objective of the present study is to develop an easy tool to determine the active sites for a given structure sensitive reaction using a simple geometric approach. For that purpose, propane dehydrogenation is chosen as test reaction and a series of monometallic $\mathrm{Pt} / \mathrm{Al}_{2} \mathrm{O}_{3}$ catalysts is prepared using a specific preparation technique, the refilling method, developed in our laboratory by Barbier and co-workers many years ago and allowing to easily control the growing of supported metal nanoparticles starting from a parent catalyst [20].

\section{Experimental}

\subsection{Catalyst preparation}

\subsubsection{Parent catalyst}

The parent catalyst (denoted $\mathrm{Pt} / \mathrm{Al}_{2} \mathrm{O}_{3}(\mathrm{RO})$ ) was prepared by impregnation of a $\mathrm{y}$-alumina support (GOD200, Axens) with a surface area of $200 \mathrm{~m}^{2} \mathrm{~g}^{-1}$. First, the support was calcined in flowing air $\left(60 \mathrm{~mL} \mathrm{~min}{ }^{-1}\right)$, for $4 \mathrm{~h}$ at a temperature of $450^{\circ} \mathrm{C}$. Secondly, the support was crushed and sieved to obtain a granulometry between 250 and $100 \mu \mathrm{m}$. Then, the support was wet with an ammonia solution at $\mathrm{pH} 11$ and a solution of diammineplatinum (II) nitrite $\left(\mathrm{Pt}\left(\mathrm{NH}_{3}\right)_{2}\left(\mathrm{NO}_{2}\right)_{2}\right.$, 1.7 wt.\% of Pt, Alfa Aesar) was added in order to obtain a metal loading of 1 wt.\%. The suspension was stirred for one night at $150 \mathrm{rpm}$ and water was removed by drying at $110^{\circ} \mathrm{C}$ for another night. Then, the catalyst was calcined under air $\left(60 \mathrm{~mL} \mathrm{~min}^{-1}\right)$ for $4 \mathrm{~h}$ at $450{ }^{\circ} \mathrm{C}$, and reduced under $\mathrm{H}_{2}(60 \mathrm{~mL} \mathrm{~min}-1)$ at $650^{\circ} \mathrm{C}$ during $4 \mathrm{~h}$. The final powder was sieved between 250 and $100 \mu \mathrm{m}$. A blank alumina support, corresponding to the support submitted to the same treatment as the one used for the preparation of the RO sample, but without the addition of the platinum salt, was also prepared.

\subsubsection{Refilling method}

The $\mathrm{Pt} / \mathrm{Al}_{2} \mathrm{O}_{3}(\mathrm{Rj})$ catalysts (where $\mathrm{j}$ represents the number of refill, $\mathrm{j}=1,2$ or 3 ) were prepared by deposition of $\mathrm{j}$ Pt layer(s) on the RO parent catalyst by a surface redox reaction, namely the refilling method.

The $\mathrm{Pt} / \mathrm{Al}_{2} \mathrm{O}_{3}(\mathrm{R} 1)$ catalyst was prepared by the following procedure: a given amount of the $\mathrm{Pt} / \mathrm{Al}_{2} \mathrm{O}_{3}(\mathrm{RO})$ catalyst was placed in a reactor, outgassed with $\mathrm{N}_{2}$ and then reduced under $\mathrm{H}_{2}(60$ $\mathrm{mL} \mathrm{min}-1$ ) during $1 \mathrm{~h}$ at $450^{\circ} \mathrm{C}$. Then, the catalyst was cooled down to room temperature under 
$\mathrm{N}_{2}$. A volume of water was added to moisten the $\mathrm{Pt} / \mathrm{Al}_{2} \mathrm{O}_{3}(\mathrm{RO})$ catalyst. The suspension of $\mathrm{Pt} / \mathrm{Al}_{2} \mathrm{O}_{3}(\mathrm{RO})$ catalyst was at first maintained under $\mathrm{H}_{2}$ flow in order to preadsorb hydrogen on the platinum surface (Eq.1) and then placed under $\mathrm{N}_{2}$ flow for 15 min to remove dissolved or weakly adsorbed hydrogen in solution and on the catalyst, respectively. Afterwards, a chloroplatinic acid solution was added and let under $\mathrm{N}_{2}$ flow in contact with the parent catalyst for $1 \mathrm{~min}$ (Eq.2). The refilling process based on a redox reaction between the hydrogen atoms adsorbed at the surface of the Pt parent catalyst and the oxidized Pt species in solution can be schematized as the following:

$2 P t_{S}+H_{2} \rightarrow 2 P t_{S}-H$

$4 P t_{S}-H+P t^{4+} \rightarrow P t-\left(P t_{S}\right)_{4}+4 H^{+}$

with Pts corresponding to surface Pt atoms.

Then the solution was filtered out to obtain the $\mathrm{Pt}_{/} \mathrm{Al}_{2} \mathrm{O}_{3}(\mathrm{R} 1)$ catalyst. This procedure was repeated 3 times, in order to obtain the $\mathrm{Pt} / \mathrm{Al}_{2} \mathrm{O}_{3}(\mathrm{R} 2)$ starting from $\mathrm{R} 1$, and then $\mathrm{Pt} / \mathrm{Al}_{2} \mathrm{O}_{3}(\mathrm{R} 3)$ starting from R2. Finally, the $\mathrm{Pt} / \mathrm{Al}_{2} \mathrm{O}_{3}(\mathrm{Rj})$ sample was dried at $100{ }^{\circ} \mathrm{C}$ for one night under $\mathrm{N}_{2}$, and then reduced under $\mathrm{H}_{2}\left(60 \mathrm{~mL} \mathrm{~min}^{-1}\right)$ during $1 \mathrm{~h}$ at $650{ }^{\circ} \mathrm{C}$.

\subsection{Catalyst characterizations}

\subsubsection{Determination of the metal content}

Inductively coupled plasma optical emission spectroscopy (ICP-OES) was used for the determination of the actual metal content of each sample. The measurements were performed with a Perkin Elmer Optima 2000DV spectrometer. The samples were previously digested in an acidic mixture of $\mathrm{HNO}_{3}$ and $\mathrm{HCl}$ under microwave heating.

\subsubsection{Transmission electron microscopy}

Transmission electron microscopy (TEM) analysis was performed with a JEOL 2100 UHR microscope equipped with an energy dispersive X-ray (EDX). Reduced catalysts were suspended in ethanol under sonication for $5 \mathrm{~min}$ and loaded on holey carbon film Cu grid (300 mesh). A minimum of four hundred particles was counted to calculate the average particle size (denoted $\left.\bar{d}_{T E M}\right)$, according to the methodology used in the Ref. [21].

\subsubsection{Hydrogen chemisorption}


Hydrogen chemisorption measurements were performed at $30{ }^{\circ} \mathrm{C}$ using a Micromeritics Autochem 2920 II apparatus. The catalyst $(0.050-0.100 \mathrm{~g})$ was introduced between two quartz wool balls into a quartz $\mathrm{U}$-shaped tube reactor and reduced for $1 \mathrm{~h}$ at $650{ }^{\circ} \mathrm{C}\left(5^{\circ} \mathrm{C} \mathrm{min} \mathrm{m}^{-1}\right.$ heating rate) under a flow of hydrogen $\left(30 \mathrm{~mL} \mathrm{~min}^{-1}\right)$, kept at this temperature for $1 \mathrm{~h}$, then purged with argon $\left(30 \mathrm{~mL} \mathrm{~min}^{-1}\right)$ at the same temperature for $1 \mathrm{~h}$. The reactor was cooled down under argon to the adsorption temperature, and the measurements were undertaken through pulse injections $(0.0551 \mathrm{~mL})$ of $10 \% \mathrm{H}_{2} / \mathrm{Ar}$ until saturation. Hydrogen consumption was monitored using a thermal conductivity detector (TCD). The particle size $(\bar{d})$ and the dispersion $(D)$ were determinate with the following equations (see Ref. [22] for more details):

$\bar{d}(n m)=\frac{1}{-0.138 \times\left(\frac{H}{P t}\right)^{5}+0.794 \times\left(\frac{H}{P t}\right)^{4}-1.469 \times\left(\frac{H}{P t}\right)^{3}+0.903 \times\left(\frac{H}{P t}\right)^{2}+0.703 \times\left(\frac{H}{P t}\right)}$

$D(\%)=-29.230 \times\left(\frac{H}{P t}\right)^{5}+134.647 \times\left(\frac{H}{P t}\right)^{4}-201.198 \times\left(\frac{H}{P t}\right)^{3}+70.105 \times\left(\frac{H}{P t}\right)^{2}+98.611 \times\left(\frac{H}{P t}\right)$ (Eq.4) where $H / P t$ represents the experimental atomic ratio obtained by chemisorption.

\subsection{Catalytic test}

Propane dehydrogenation reaction was carried out in a conventional fixed-bed reactor. The mass of sample was adjusted in order to obtain a constant Pt loading in the reactor $(0.3 \mathrm{mg})$. A mass of blank alumina was added to the sample in order to maintain a total mass (catalyst + blank alumina) of $100 \mathrm{mg}$ for each experiment. Then, the mixture was mixed with carborundum (SiC) (total catalytic bed of $3 \mathrm{~cm}$ height) and in situ prereduced under $\mathrm{H}_{2}\left(60 \mathrm{~mL} \mathrm{~min}^{-1}\right)$ at 650 ${ }^{\circ} \mathrm{C}$ for $1 \mathrm{~h}$. After reduction, the reaction gas mixture was introduced at $575^{\circ} \mathrm{C}$ at a flowrate of $100 \mathrm{~mL} \mathrm{~min}{ }^{-1}$. The gas mixture was composed of $50 \% \mathrm{C}_{3} \mathrm{H}_{8}, 45 \% \mathrm{~N}_{2}$ and $5 \% \mathrm{H}_{2}$ corresponding to a molar ratio of 10:9:1. The flowrate at the outlet was measured on line using a Ritter Gas Meter. The outlet gas composition was analyzed by an online Agilent 7820A gas chromatography equipped with an FID and $\mathrm{HP}-\mathrm{Al}_{2} \mathrm{O}_{3} / \mathrm{KCl}$ capillary column. Propane conversion $(X)$, activity in propane conversion $\left(A_{C_{3} H_{8}}\right)$, propane turn over frequency $\left(\right.$ TOF $\left._{C_{3} H_{8}}\right)$ and selectivity to each product $\mathrm{C}_{x} \mathrm{H}_{\mathrm{y}}\left(S_{C_{x} H_{y}}\right)$ in gas phase were calculated as follows:

$$
\begin{aligned}
& X(\%)=\frac{F_{C_{3} H_{8 i n}}-F_{C_{3} H_{8} \text { out }}}{F_{C_{3} H_{8} \text { in }}} \times 100 \\
& A_{C_{3} H_{8}}\left(m o l h^{-1} g_{P t}^{-1}\right)=\frac{X \times F_{C_{3} H_{8} \text { in }}}{m_{\text {cata }} \times \%_{P t}} \\
& T O F_{C_{3} H_{8}}\left(s^{-1}\right)=\frac{A_{C_{3} H_{8}} \times M_{P t}}{D \times 10^{-2} \times 3600}
\end{aligned}
$$


$S_{C_{x} H_{y}}(\%)=\frac{x \times F_{C_{x} H_{y}}}{\Sigma\left(x \times F_{C_{x} H_{y}}\right)} \times 100$

where $F_{C_{3} H_{8}}$ corresponds to the molar flowrate $\left(\mathrm{mol} \mathrm{h}^{-1}\right)$ of propane, and $F_{C_{x} H_{y}}$ refers to the molar flow rate $\left(\mathrm{mol} \mathrm{h}^{-1}\right)$ of all the products identified at the outlet $\left(\mathrm{C}_{3} \mathrm{H}_{6}, \mathrm{C}_{2} \mathrm{H}_{6}, \mathrm{C}_{2} \mathrm{H}_{4}\right.$ and $\left.\mathrm{CH}_{4}\right)$; in and out are associated to the molar flowrate at the inlet and at the outlet, respectively; $x$ and $y$ are the number of carbon and hydrogen atoms in the molecule, respectively; $m_{\text {cata }}$ is the mass (g) of catalyst and \%pt the Pt content (wt.\%) in the catalyst; $D$ represents the metal dispersion (\%) and $\mathrm{MPt}_{\mathrm{Pt}}$ the molar weight of platinum $\left(\mathrm{g} \mathrm{mol}^{-1}\right)$.

\section{Results and discussion}

\subsection{Description of the model and determination of surface site concentration}

\subsubsection{Relationship between the crystallite shape, the metallic crystallite size and the parameter}

\section{m}

As in our last paper based on the same geometric approach [23], the shape of the Pt crystallites was assumed to be a fcc perfect truncated octahedron (denoted TO, see figure in Table 1). The perfect truncated octahedron is the most common shape admitted in the literature for a crystallized fcc structure of metals like Pt $[12,15]$. The perfect TO presents 14 faces divided in two types, 8 hexagonal faces with a (111) symmetry and 6 squares with a (100) symmetry. For a given size, the TO is characterized by a parameter $m$. This parameter $m(m \geq 2)$ is the number of atoms lying on an equivalent edge, corner atoms included, of the chosen crystallite. For example, the value of the parameter $m$ for truncated octahedron represented in Table 1 is 3 . Knowing the value of the parameter $\mathrm{m}$, it is possible to obtain directly the crystallite size (denoted d in Table 1), or conversely knowing the value of $d$, it is possible to obtain directly the value of parameter $m$ with the equations given in Table 1 [23]. However, these definitions are true only if the studied particle sizes allow to obtain an integer for the $m$ parameter. This problem is easily circumvented by using the average particle size (denoted $\bar{d}$ ) by assuming that it is a distribution of $\mathrm{k}$ particles with different sizes (denoted $d_{k}$ ) of $m_{k}$ integer parameters.

The average particle size is then obtained using the following equation:

$\bar{d}=3 \times d_{P t} \times(\bar{m}-1)$

with $\bar{m}=\sum_{k=1}^{n}\left(x_{k} \times m_{k}\right)$

where, $\bar{m}$ and $x_{k}$ represent the average $\mathrm{m}$ parameter and the relative number of $\mathrm{k}$ particles enumerated in the total population. 
Knowing the value of $\bar{d}$, it is possible to obtain directly the value of $\bar{m}$ parameter with Eq.10.

$\bar{m}=\frac{\bar{d}}{3 \times d_{P t}}+1$

\subsubsection{Relationship between the crystallite shape, the atom population and the parameter $m$}

Based on the works of Van Hardeveld and Hartog [9], we developed a simple model to describe the evolution of the surface structure (corners, edges, faces (100) and faces (111)) for unsupported perfect fcc crystallites with the evolution of the crystallite size, as already described in our reference [23]. Each size is characterized by different atom populations: the total number of atoms (denoted $\mathrm{N}_{\mathrm{T}}$ ), the number of surface atoms (denoted $\mathrm{N}_{\mathrm{S}}$ ), the number of bulk atoms (denoted $\mathrm{N}_{\mathrm{B}}$ ) and the number of atoms with i coordination (denoted $\mathrm{N}_{\mathrm{C}}$ and corresponding to the atoms occupying the corners, edges and faces, respectively). The $\mathrm{N}_{T}$ and $N_{B}$ values are given by third order polynomial in $m$, whereas $N_{S}$ is given by a second order polynomial in $\mathrm{m}$. In addition, the $\mathrm{N}_{\mathrm{Ci}}$ are given by a zero, first or second order polynomial in $\mathrm{m}$. All the $N_{T}, N_{S}, N_{B}$ and $N_{C i}$ formulas, for the TO, are listed in Table 1. 
Table 1. Formulae used to calculate all parameters required to describe the geometrical model based on truncated octahedron $\left(d_{P t}=0.279 \mathrm{~nm}, M_{P t}=195.08 \mathrm{~g} \mathrm{~mol}^{-1} ; \mathrm{H}\right.$ : hexagonal and $\mathrm{S}$ : square). Illustration: truncated octahedron with parameter $m=3$; numbers 6 (gray), 7 (red), 8 (blue), 9 (green) and 12 (black) represent the coordination numbers of the atoms located in the corners, edges, faces (100), faces (111) and bulk, respectively.

\begin{tabular}{|c|c|c|c|c|}
\hline Parameter & Symbol & Formula & Location & Ref. \\
\hline Particle size (nm) & d & $3 \times d_{P t} \times(m-1)$ & - & \multirow[b]{2}{*}[23]{} \\
\hline Parameter m & $\mathrm{m}$ & $\frac{d}{3 \times d_{P t}}+1$ & $-\infty$ & \\
\hline Total number of atoms & $N_{T}$ & $16 \times m^{3}-33 \times m^{2}+24 \times m-6$ & & \multirow{8}{*}{ [9] } \\
\hline $\begin{array}{l}\text { Total number of surface } \\
\text { atoms }\end{array}$ & $N_{S}$ & $30 \times m^{2}-60 \times m+32$ & Surface & \\
\hline Number of bulk atoms & $N_{B}$ & $16 \times m^{3}-63 \times m^{2}+84 \times m-38$ & Bulk & \\
\hline \multirow{5}{*}{$\begin{array}{l}\text { Number of surface } \\
\text { atoms }\end{array}$} & $N_{C 6}$ & 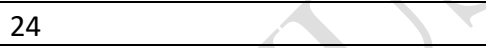 & Corner & \\
\hline & $N_{C 7}^{(H-H)}$ & $12 \times(m-2)$ & Edge $\mathrm{H}-\mathrm{H}$ & \\
\hline & $N_{C 7}^{(H-S)}$ & $24 \times(m-2)$ & Edge $\mathrm{H}-\mathrm{S}$ & \\
\hline & $N_{C 8}$ & $6 \times(m-2)^{2}$ & Face (100) & \\
\hline & $N_{C 9}$ & $8 \times\left(3 \times m^{2}-9 \times m+7\right)$ & Face (111) & \\
\hline & $\theta_{C 6}$ & $1-\frac{S A_{C 6}}{4 \pi}$ & Corner & \\
\hline & $\theta_{C 7}^{(H-H)}$ & $1-\frac{D A_{C 7}^{(H-H)}}{2 \pi}$ & Edge $\mathrm{H}-\mathrm{H}$ & \\
\hline $\begin{array}{l}\text { Fraction of accessible } \\
\text { surface atoms }\end{array}$ & $\theta_{C 7}^{(H-S)}$ & $1-\frac{D A_{C 7}^{(H-S)}}{2 \pi}$ & Edge H-S & \\
\hline & $\theta_{C 8}$ & $\frac{1}{2}$ & Face (100) & {$[24]$} \\
\hline & $\theta_{C 9}$ & $\frac{1}{2}$ & Face (111) & \\
\hline Solid angle (sr) & $S A_{C 6}$ & $\pi$ & Corner & \\
\hline Dihedral angle (rad) & $D A_{C 7}^{(H-H)}$ & $2 \tan ^{-1}(\sqrt{2})$ & Edge $\mathrm{H}-\mathrm{H}$ & \\
\hline Dihedral angle (rad) & $D A_{C 7}^{(H-S)}$ & $\pi-\tan ^{-1}(\sqrt{2})$ & Edge H-S & \\
\hline & $N_{\text {C6acc }}$ & $N_{C 6} \times \theta_{C 6}$ & Corner & \\
\hline Number of accessible & $N_{C 7 a c c}^{(H-H)}$ & $N_{C 7}^{(H-H)} \times \theta_{C 7}^{(H-H)}$ & Edge $\mathrm{H}-\mathrm{H}$ & \\
\hline surface atoms & $N_{C 7 a c c}^{(H-S)}$ & $N_{C 7}^{(H-S)} \times \theta_{C 7}^{(H-S)}$ & Edge H-S & {$[23]$} \\
\hline sumace acums & $N_{C 8 a c c}$ & $N_{C 8} \times \theta_{C 8}$ & Face (100) & \\
\hline & $N_{C 9 a c c}$ & $N_{C 9} \times \theta_{C 9}$ & Face (111) & \\
\hline & {$\left[N_{\text {C6acc }}\right]$} & $\frac{N_{C 6 a c c}}{N_{T} \times M_{P t}}$ & Corner & \\
\hline & {$\left[N_{C 7 a c c}^{(H-H)}\right]$} & $\frac{N_{C 7 a c c}^{(H-H)}}{N_{T} \times M_{P t}}$ & Edge $\mathrm{H}-\mathrm{H}$ & $\begin{array}{l}\text { New } \\
\text { parameter }\end{array}$ \\
\hline $\begin{array}{l}\text { Accessible surface atom } \\
\left.\text { concentration (mol } g_{P t}^{-1}\right)\end{array}$ & {$\left[N_{C 7 a c c}^{(H-S)}\right]$} & $\frac{N_{C 7 a c c}^{(H-S)}}{N_{T} \times M_{P t}}$ & Edge H-S & $\begin{array}{l}\text { parameter } \\
\text { introduced } \\
\text { in this }\end{array}$ \\
\hline & {$\left[N_{C 8 a c c}\right]$} & $\frac{N_{C 8 a c c}}{N_{T} \times M_{P t}}$ & Face $(100)$ & work \\
\hline & {$\left[N_{C 9 a c c}\right]$} & $\frac{N_{C 9 a c c}}{N_{T} \times M_{P t}}$ & Face (111) & \\
\hline
\end{tabular}




\subsubsection{Relationship between the surface site concentration and the crystallite size}

For each crystallite size, it is possible to determine the fraction of accessible surface atoms for each i coordination (denoted $\theta_{\mathrm{Ci}}$ and expressed in fraction of sphere) [24] using the equations listed in Table 1, where SAc6 and DAc7 represent the solid angle subtended at corner atoms and the dihedral angle corresponding to the intersection between two faces on a given edge, respectively. The solid angle (expressed in steradians) and the dihedral angle (expressed in radians) are obtained from the equations listed in Table 1 [24].

Knowing the values of $\mathrm{N}_{\mathrm{Ci}}$ and $\theta_{\mathrm{Ci}}$, it is possible to calculate the number of accessible surface atoms (denoted $\mathrm{N}_{\text {ciacc }}$ in Table 1) and the accessible surface atom concentration (denoted $\left[\mathrm{N}_{\text {ciacc }}\right]$ in Table 1). The [ $\left.\mathrm{N}_{\text {ciacc }}\right]$ values constitute a new parameter in our geometric model approach.

The surface site concentrations (denoted [site], where site = corner, edge, face $(100)$ or face(111)) of one Pt particle with a given $m$ value, can then be obtained using the following equations (Eqs.11-14):

[corner $]=\left[N_{\text {C6acc }}\right]$

$[$ edge $]=\left[N_{C 7 a c c}^{(H-H)}\right]+\left[N_{C 7 a c c}^{(H-S)}\right]$

$[\operatorname{face}(100)]=\left[N_{C 8 a c c}\right]$

$[\operatorname{face}(111)]=\left[N_{C 9 a c c}\right]$

The evolution of surface site concentrations versus particle size is presented in Fig.1. For the smallest Pt particle size $(d=0.84 \mathrm{~nm})$, the corner sites are the main sites present on the particle surface $\left(2428.2 \mu \mathrm{mol} g_{P t}^{-1}\right)$. As the metal particle size increases, there is an obvious decrease of the concentration of corner sites in favor of the edges, face (100), and face (111) sites. One can see that the edge, face (111), and face (100) site concentrations reach a maximum value (647.1, 714.1 and $107.9 \mu \mathrm{mol} g_{P t}^{-1}$, respectively) with Pt particle size equal precisely to 1.39, 1.69 and $3.04 \mathrm{~nm}$, respectively, whereas the corners concentration monotonously decreases. 


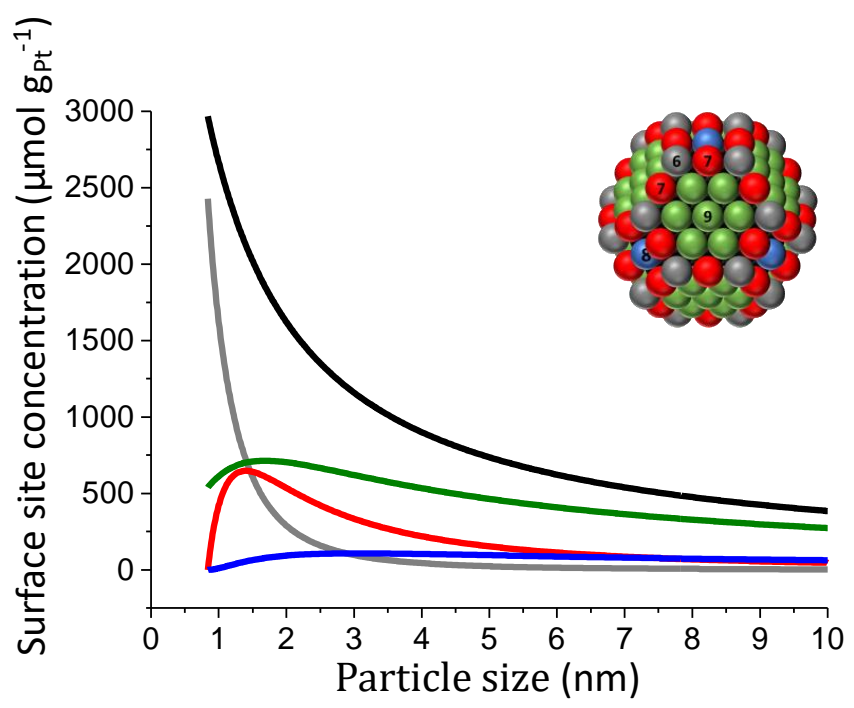

Fig.1. Evolution of the surface site concentration in function of the particle size for a fcc perfect truncated octahedron (black: all sites; grey: corners; red: edges; blue: faces (100) and green: faces (111)).

In terms of metal catalytic activity for a given reaction, it is expected that atoms with low coordination number ( 6 and 7 for corner and edge, respectively) are the most prone to chemisorb substrates since these atoms tend to complete their coordination to 12 . In this sense, the surface site concentration presented in Fig.1 can be seen as a picture of a metallic catalyst activity per gram of metal. To validate this hypothesis, it is necessary to have available catalytic materials with particle size perfectly controlled and to evaluate them catalytically with a structure sensitive reaction, what will be the subject of the following.

\subsection{Refilling method}

\subsubsection{Principle}

Catalysts of various particle sizes are of great interest to understand the structure effects on activity, selectivity and deactivation of the metallic particles. Four decades ago, to achieve this purpose, our laboratory developed a preparation process named the refilling method [25]. This method consists in reducing $\mathrm{Pt}^{\mathrm{n}+}$ ions by hydrogen preadsorbed on the metallic particles of a $\mathrm{Pt} / \mathrm{Al}_{2} \mathrm{O}_{3}$ parent catalyst [20] (see Fig.2). 


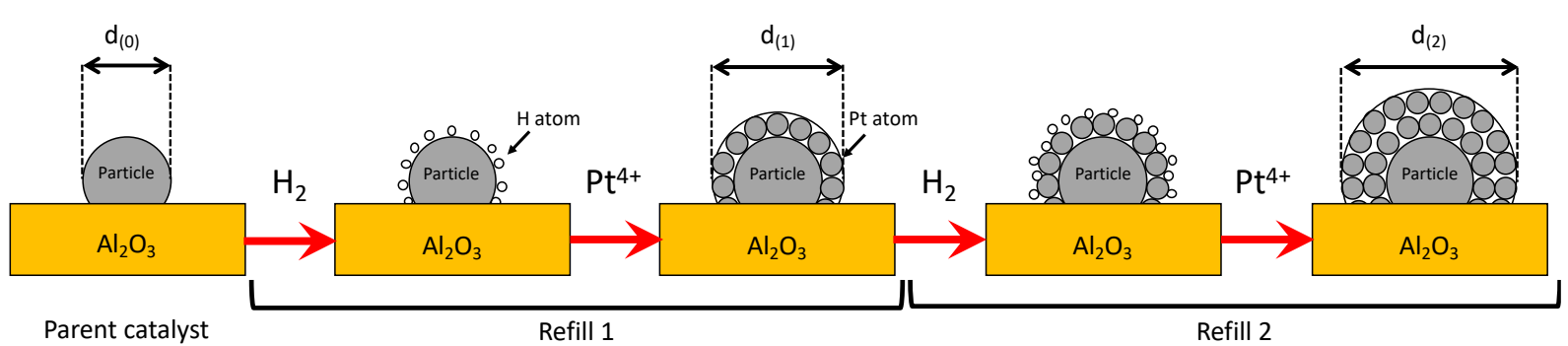

Fig.2. Principle of the refilling method.

By adding the appropriate $\mathrm{Pt}^{\mathrm{n}+}$ amount ( $\mathrm{Pt}^{4+}$ in our case), this surface reduction induces a uniform growth of the Pt particles. The expected diameter of these particles can be estimated using the following equation:

$d_{(j)}=2 \times j \times d_{P t}+d_{(0)}$

where $j$ and $d_{(0)}$ represent the number of refills ( $j=1,2$ and 3 in this work) and the parent catalyst particle size, respectively.

Assuming that the shape of the particles is a TO, whatever the particle size, it is possible to calculate the expected amount of $\mathrm{Pt}^{4+}$ needed to form a monolayer around the particles of the parent catalyst. This expected amount of $\mathrm{Pt}^{4+}$ (denoted $\left.m_{P t^{4+}(j)}\right)$ and the total expected amount of Pt on the catalyst (denoted $m_{P t(j)}$ ) can be calculated using the Eq.16 and Eq.17.

$m_{P t^{4+}(j)}=m_{P t(j-1)} \times \frac{N_{S(j)}}{N_{B(j)}}$

$m_{P t(j)}=m_{P t(j-1)}+m_{P t^{4+}(j)}$

where $N_{S(j)}$ and $N_{B(j)}$ represent the total surface atoms number and the bulk atoms number for one particle after the refill $\mathrm{j}\left(N_{S(j)}\right.$ and $N_{B(j)}$ are calculated with the formulae of Table 1 for a given $d_{(j)}$ and $j=1,2$ and 3 in this work).

An example of calculation is presented in Table 2.

Table 2. Predicted particle sizes and calculated amounts of $\mathrm{Pt}$ and $\mathrm{Pt}^{4+}$ for each $\mathrm{j}$ refill performed on $0.8 \mathrm{~g}$ of parent catalyst 1.07 wt.\% Pt/Al $\mathrm{O}_{3}(\mathrm{RO})$.

\begin{tabular}{|c|c|c|c|c|c|}
\hline Catalyst & j & $\begin{array}{c}\mathrm{d}_{(\mathrm{j})} \\
(\mathrm{nm})\end{array}$ & $\frac{N_{S(j)}}{N_{B(j)}}$ & $\begin{array}{c}m_{P t(j)} \\
(\mathrm{g})\end{array}$ & $\begin{array}{c}m_{P t^{4+}(j)} \\
(\mathrm{g})\end{array}$ \\
\hline $\mathrm{Pt} / \mathrm{Al}_{2} \mathrm{O}_{3}(\mathrm{RO})$ & 0 & 0.95 & - & $8.5610^{-3}$ & - \\
\hline $\mathrm{Pt} / \mathrm{Al}_{2} \mathrm{O}_{3}(\mathrm{R} 1)$ & 1 & 1.51 & 1.82 & $2.4110^{-2}$ & $1.5610^{-2}$ \\
\hline $\mathrm{Pt} / \mathrm{Al}_{2} \mathrm{O}_{3}(\mathrm{R} 2)$ & 2 & 2.07 & 1.13 & $5.1410^{-2}$ & $2.7310^{-2}$ \\
\hline $\mathrm{Pt} / \mathrm{Al}_{2} \mathrm{O}_{3}(\mathrm{R} 3)$ & 3 & 2.62 & 0.82 & $9.3510^{-2}$ & $4.2010^{-2}$ \\
\hline
\end{tabular}




\subsubsection{Characterizations of the catalysts}

All the characteristics of the various studied catalyst $\mathrm{Pt} / \mathrm{Al}_{2} \mathrm{O}_{3}(\mathrm{Rj})$ are reported in Table 3 .

TEM images of selected fresh catalysts (the first and the last of the series) are presented in Fig.3. The measured metal content for $\mathrm{Pt} / \mathrm{Al}_{2} \mathrm{O}_{3}(\mathrm{RO})$ (parent catalyst, $1.07 \mathrm{wt} . \%$ ) is similar to the targeted one (1 wt.\%). The particle size of the $\mathrm{Pt} / \mathrm{Al}_{2} \mathrm{O}_{3}(\mathrm{RO})$ catalyst determined from $\mathrm{H}_{2}$ chemisorption $(0.95 \mathrm{~nm})$ is quite close to the value determined from TEM images $(1.30 \mathrm{~nm})$, but lower. The measured metal content for $\mathrm{Pt}_{\mathrm{Al}} \mathrm{Al}_{3}(\mathrm{Rj}$ ) catalysts (with $\mathrm{j}=1,2$ or 3 ) increases with the $\mathrm{j}$ number of refills performed on the parent catalyst. The particle diameters of the refilled catalysts determined from $\mathrm{H}_{2}$ chemisorption are between 1.44 and $2.62 \mathrm{~nm}$, the value growing with the j number of refills. These results are in perfect agreement with the predicted $d_{(j)}$ values (Table 2), clearly indicating the selective deposition of Pt allowing the formation of the monolayer.

Table 3. Characteristics of $\mathrm{Pt} / \mathrm{Al}_{2} \mathrm{O}_{3}(\mathrm{Rj})$ catalysts.

\begin{tabular}{lcccccc}
\hline Catalyst & $\begin{array}{c}\text { \% } \mathrm{Pt}^{\mathrm{a}} \\
(\mathrm{wt} . \%)\end{array}$ & $\mathrm{H} / \mathrm{Pt}^{\mathrm{b}}$ & $\begin{array}{c}\bar{d}^{\mathrm{b}} \\
(\mathrm{nm})\end{array}$ & $\begin{array}{c}\mathrm{D}^{\mathrm{b}} \\
(\%)\end{array}$ & $\begin{array}{c}\bar{d}_{\text {TEM }} \\
(\mathrm{nm})\end{array}$ & $\begin{array}{c}\bar{d}_{\text {TEM }} \\
(\mathrm{nm})\end{array}$ \\
\hline $\mathrm{Pt} / \mathrm{Al}_{2} \mathrm{O}_{3}(\mathrm{RO})$ & 1.07 & 1.44 & 0.95 & 84.4 & 1.30 & 2.96 \\
$\mathrm{Pt}_{\mathrm{Al}} \mathrm{O}_{3}(\mathrm{R} 1)$ & 2.02 & 0.84 & 1.44 & 68.0 & - & - \\
$\mathrm{Pt} / \mathrm{Al}_{2} \mathrm{O}_{3}(\mathrm{R} 2)$ & 3.20 & 0.59 & 1.94 & 55.7 & - & - \\
$\mathrm{Pt} / \mathrm{Al}_{2} \mathrm{O}_{3}(\mathrm{R} 3)$ & 4.87 & 0.44 & 2.62 & 44.0 & 3.06 & 3.45 \\
\hline
\end{tabular}

a Pt content determined by ICP-OES, standard deviations lie in the $\pm 2 \%$ range.

${ }^{\mathrm{b}} \mathrm{H} / \mathrm{Pt}$ ratio, average particle diameter and dispersion $\mathrm{D}$ determined by hydrogen chemisorption.

${ }^{c}$ Average particle diameter determined by TEM after PDH reaction. 

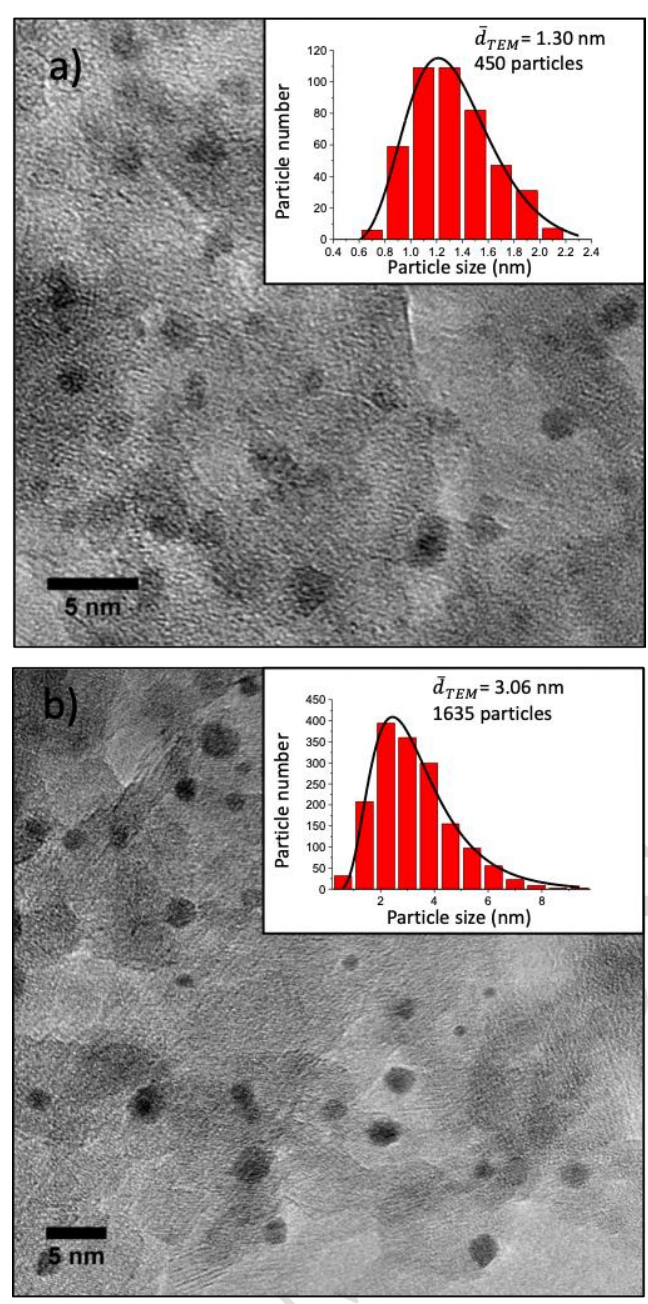

Fig.3. TEM images and particle size distributions of fresh Pt catalysts (a: $\mathrm{Pt} / \mathrm{Al}_{2} \mathrm{O}_{3}(\mathrm{RO})$ and b: $\mathrm{Pt} / \mathrm{Al}_{2} \mathrm{O}_{3}(\mathrm{R} 3)$ ).

As for the R0 sample, the size determined from $\mathrm{H}_{2}$ chemisorption for the $\mathrm{Pt} / \mathrm{Al}_{2} \mathrm{O}_{3}(\mathrm{R} 3)$ sample is lower than that determined from the TEM images. This difference can be explained easily taking into account the discrepancy between the geometric model used for the determination of the size from $\mathrm{H}_{2}$ chemisorption based on the distances between the center of Pt atoms, and the TEM diameter determined at the external surface of the particle. Thus, this difference is constant whatever the particle size and is of the same order as the diameter of one Pt atom as illustrated in Fig.4. Consequently, it is then possible to predict the diameter of the Pt nanoparticles knowing the number of refills, making sure that the particle diameters of the parent catalyst were determined according the same methodology. In the following, the used particle sizes will be those determined from $\mathrm{H}_{2}$ chemisorption. 


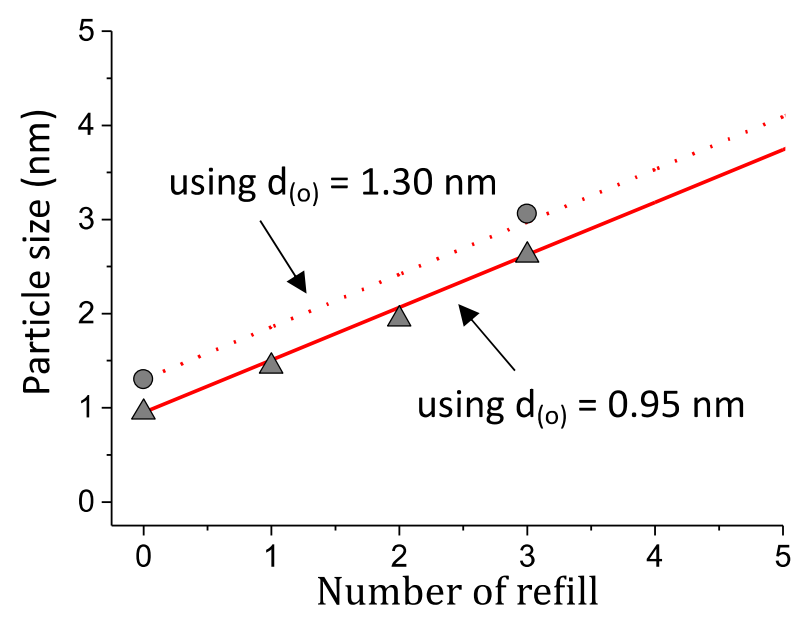

Fig.4. Evolution of the particle size in function of the $\mathrm{j}$ number of refill (triangle: size determined from $\mathrm{H}_{2}$ chemisorption; circle: size determined from TEM; red line: predicted particle size with $d_{(0)}=0.95 \mathrm{~nm}$; red dotted line: predicted particle size with $\mathrm{d}(0)=1.30 \mathrm{~nm})$.

\subsection{Effect of the platinum particle size on the propane dehydrogenation}

The series of catalysts was evaluated in propane dehydrogenation at $575{ }^{\circ} \mathrm{C}$. The activity as a function of time on stream, the initial TOF and the $\mathrm{C}_{3} \mathrm{H}_{6}$ selectivity as function of the particle size are presented in Fig.5.

Fig.5a shows the initial $\mathrm{C}_{3} \mathrm{H}_{8}$ activity decreases with the increase of particle size $(139.2,73.6$, 41.8 and $26.0 \mathrm{~mol} \mathrm{~h}^{-1} \mathrm{gPt}^{-1}$ for $0.95,1.44,1.94$ and $2.62 \mathrm{~nm}$, respectively), in accordance with the results of [17]. One can note that, for all the Pt catalysts, a deactivation is observed as a function of time on stream, characterized by a decrease of the $\mathrm{C}_{3} \mathrm{H}_{8}$ activity until a plateau, more sever on smaller particles (the same trend is observed for the conversion of propane, see Fig.S.1. in Supporting Information). The difference between the initial $\mathrm{C}_{3} \mathrm{H}_{8}$ activity and the


inserted figure in Fig.5a). $\Delta \mathrm{A}_{\mathrm{c} 3 \mathrm{H} 8}$ increases with the decrease of the particle size, indicating a coke deposit preferentially occurring on the corner and/or edge metal atoms [18], and/or a phenomenon of sintering on the smallest particles. TEM images of catalysts after PDH reaction are presented in Fig.S.2 (in Supporting Information). The values of particle size determined by TEM (listed in Table 3) show a sintering of the metal particles from 1.30 to $2.96 \mathrm{~nm}$ and 3.06 to 3.45 for the $\mathrm{Pt} / \mathrm{Al}_{2} \mathrm{O}_{3}(\mathrm{RO})$ and $\mathrm{Pt} / \mathrm{Al}_{2} \mathrm{O}_{3}(\mathrm{R} 3)$ samples, respectively, indicating the existence of a sintering preferentially more pronounced on the smallest particles. TEM and EDX analyses confirmed also the presence of carbon on the used catalysts. 
In order to study the effect of particle size on PDH reactivity, it is absolutely necessary to get rid of the deactivation phenomenon (coke deposit and/or sintering), which would lead to errors of interpretation, and use the reactivity data referring exclusively to the initial time.

Fig.5b shows the initial $T O F_{C_{3} H_{8}}$ values and the initial $\mathrm{C}_{3} \mathrm{H}_{6}$ selectivity (denoted $S_{C_{3} H_{6}}$ ) obtained with the different catalysts. The initial $\mathrm{TOF}_{\mathrm{C}_{3} \mathrm{H}_{8}}$ decreases with the increase of particle size $\left(8.93,5.86,4.07\right.$ and $3.21 \mathrm{~s}^{-1}$ for $0.95,1.44,1.94$ and $2.62 \mathrm{~nm}$, respectively), indicating clearly that propane dehydrogenation is a structure sensitive reaction. However, no change in propylene selectivity (around 93-95\%) as a function of particle size is observed, unlike Zhu et al. results [18]. DFT results of Zhu et al. [18] shown that Pt particles of small sizes, with (211) dominating on the surface, have a lower dehydrogenation energy barrier and thus lead to higher activity than (111) and (100) surfaces. However, these authors observed higher selectivity toward propylene for large Pt clusters, for which the $\mathrm{Pt}(111)$ dominating results in a weakened binding strength of propylene and an increased energy barrier for the activation of $\mathrm{C}-\mathrm{H}$ bonds, then lowering the possibility of deep dehydrogenation of propylene. 

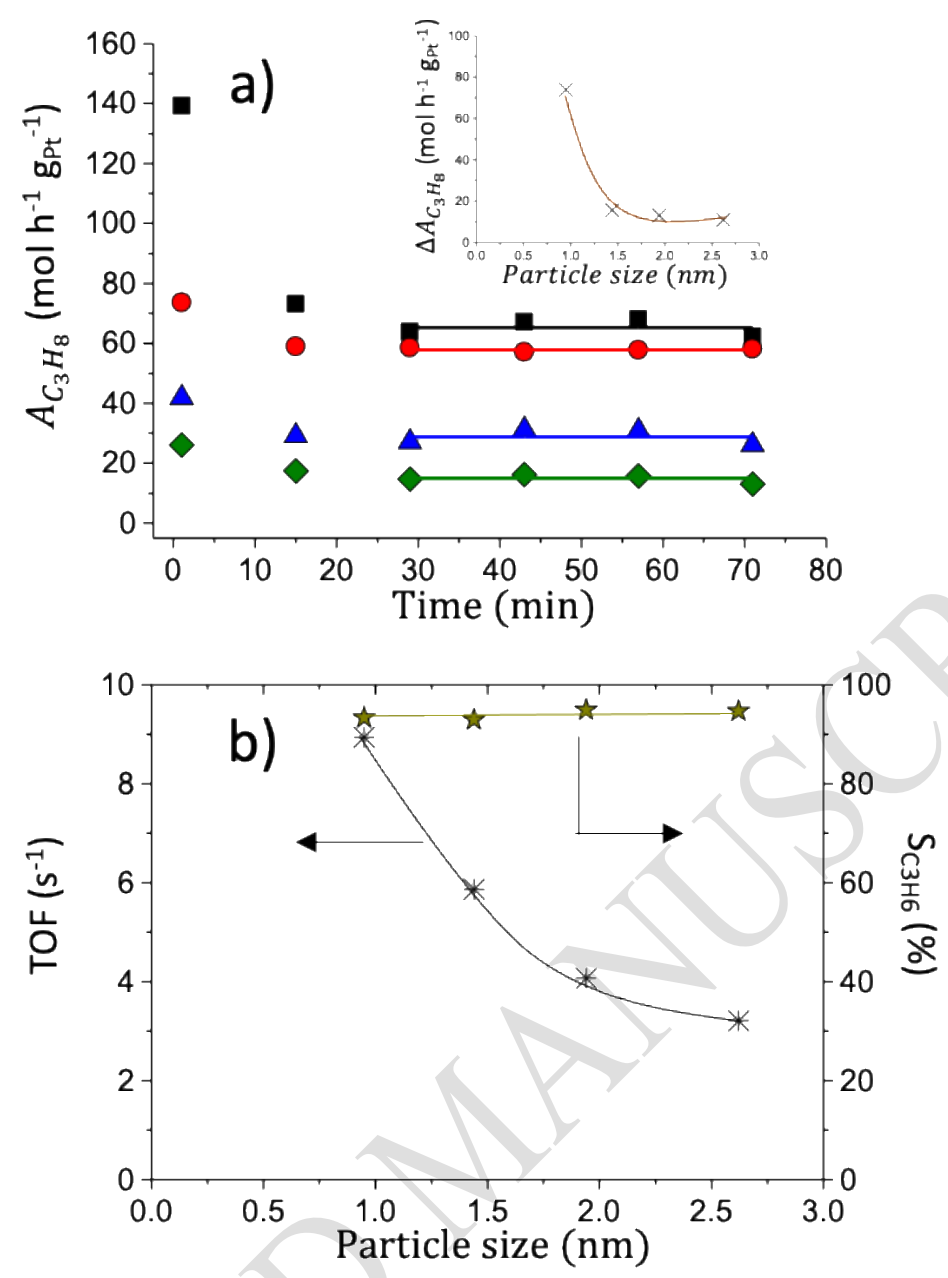

Fig.5. a): Evolution of the activity in function of the time on stream (square: $P t / A_{2} \mathrm{O}_{3}(\mathrm{RO})$; circle: $\mathrm{Pt} / \mathrm{Al}{ }_{2} \mathrm{O}_{3}(\mathrm{R} 1)$; triangle: $\mathrm{Pt} / \mathrm{Al}_{2} \mathrm{O}_{3}(\mathrm{R} 2)$; lozenge: $\mathrm{Pt} / \mathrm{Al}_{2} \mathrm{O}_{3}(\mathrm{R} 3)$ ); b) Evolution of the initial TOF and initial propene selectivity in function of the particle size.

\subsection{Relationship between activity and surface site concentration}

Activity of heterogeneous catalysts depends on the amounts of chemisorbed molecules, which themselves depend on the amount of surface sites. In this sense, the surface site concentrations presented in Fig.1 can be seen as a picture of a metallic catalyst activity per gram of Pt. As demonstrated by Calle-Vallejo et al. [14,15], all the energy considerations (adsorption, activation...) are intrinsically linked to the nature of the considered metal but also to the geometry of the active site. Assuming that the chosen surface sites have the same energetics for adsorption (whatever the metal particle size), and the adsorbed molecules do not interact with each other, the activity can then be expressed as a function of the surface site concentration (Eq.18).

$A_{C_{3} H_{8}}=f([$ site $])$ 
To validate this hypothesis, we compared the evolution of the normalized initial activity (denoted $A_{C_{3} H_{8}}^{n o r m}$, determined with the Eq.19) with the normalized surface site concentration (denoted $[\text { site }]^{\text {norm }}$, determined with the Eq.20) in function of the particle size.

$A_{C_{3} H_{8}}^{\text {norm }}=\frac{A_{C_{3} H_{8}}}{A_{C_{3} H_{8}}^{r e f}}$

$[\text { site }]^{\text {norm }}=\frac{[\text { site }]}{[\text { site }]^{\text {ref }}}$

where $A_{C_{3} H_{8}}^{r e f}$ represents the reference activity corresponding to the one of the parent catalyst (in our case $139.2 \mathrm{~mol} \mathrm{~h}^{-1} \mathrm{gPt}^{-1}$ for $\mathrm{Pt} / \mathrm{Al}_{2} \mathrm{O}_{3}(\mathrm{RO})$ ), and $[\text { site }]^{\text {ref }}$ corresponds to the reference surface site concentrations associated to the particle size of the RO sample, i.e. $\bar{d}=0.95 \mathrm{~nm}$ (see the highlighted values in Table 4 gathering the surface site concentrations calculated in function of the particle diameter).

Table 4. Surface site concentrations as function of the particle size and normalized values calculated for this study (using as reference the values highlighted in gray attributed to the parent RO catalyst).

\begin{tabular}{|c|c|c|c|c|c|c|c|c|c|c|c|c|c|c|}
\hline \multirow[b]{2}{*}{$\bar{d}(\mathbf{n m})$} & \multicolumn{7}{|c|}{ Surface site concentration $\left(\mu m o l g_{P t}^{-1}\right)$} & \multicolumn{7}{|c|}{ Normalized surface site concentration } \\
\hline & $\begin{array}{c}\text { Corner } \\
+ \\
\text { Edge } \\
+ \\
\text { Faces }\end{array}$ & Corner & Edge & $\begin{array}{l}\text { Face } \\
(\mathbf{1 0 0})\end{array}$ & $\begin{array}{l}\text { Face } \\
\text { (111) }\end{array}$ & $\begin{array}{c}\text { Corner } \\
+ \\
\text { Edge }\end{array}$ & $\begin{array}{c}\text { Face } \\
(100) \\
+ \\
\text { Face } \\
(111)\end{array}$ & $\begin{array}{c}\text { Corner } \\
+ \\
\text { Edge } \\
+ \\
\text { Faces }\end{array}$ & Corner & Edge & $\begin{array}{l}\text { Face } \\
(100)\end{array}$ & $\begin{array}{l}\text { Face } \\
\text { (111) }\end{array}$ & $\begin{array}{c}\text { Corner } \\
+ \\
\text { Edge }\end{array}$ & $\begin{array}{c}\text { Face } \\
(100) \\
+ \\
\text { Face } \\
(111)\end{array}$ \\
\hline 0.84 & 2967.7 & 2428.2 & 0.0 & 0.0 & 539.6 & 2428.2 & 539.6 & 1.08 & 1.33 & 0.00 & 0.00 & 0.91 & 1.13 & 0.90 \\
\hline 0.85 & 2941.5 & 2346.6 & 48.6 & 0.1 & 546.2 & 2395.2 & 546.2 & 1.07 & 1.29 & 0.15 & 0.02 & 0.92 & 1.11 & 0.91 \\
\hline 0.86 & 2921.6 & 2286.4 & 83.8 & 0.3 & 551.1 & 2370.2 & 551.4 & 1.06 & 1.25 & 0.25 & 0.05 & 0.93 & 1.10 & 0.92 \\
\hline 0.87 & 2901.9 & 2228.2 & 117.1 & 0.6 & 556.0 & 2345.3 & 556.6 & 1.05 & 1.22 & 0.36 & 0.11 & 0.94 & 1.09 & 0.93 \\
\hline 0.88 & 2882.5 & 2171.9 & 148.8 & 1.0 & 560.8 & 2320.7 & 561.8 & 1.05 & 1.19 & 0.45 & 0.18 & 0.95 & 1.08 & 0.94 \\
\hline 0.89 & 2863.2 & 2117.5 & 178.8 & 1.4 & 565.6 & 2296.2 & 567.0 & 1.04 & 1.16 & 0.54 & 0.25 & 0.95 & 1.07 & 0.95 \\
\hline 0.90 & 2844.3 & 2064.8 & 207.2 & 1.9 & 570.3 & 2272.1 & 572.2 & 1.03 & 1.13 & 0.63 & 0.35 & 0.96 & 1.05 & 0.96 \\
\hline 0.91 & 2825.5 & 2013.9 & 234.2 & 2.6 & 574.8 & 2248.1 & 577.4 & 1.03 & 1.10 & 0.71 & 0.47 & 0.97 & 1.04 & 0.97 \\
\hline 0.92 & 2807.0 & 1964.7 & 259.8 & 3.2 & 579.4 & 2224.4 & 582.6 & 1.02 & 1.08 & 0.79 & 0.58 & 0.98 & 1.03 & 0.97 \\
\hline 0.93 & 2788.7 & 1917.0 & 284.0 & 3.9 & 583.8 & 2201.0 & 587.7 & 1.01 & 1.05 & 0.86 & 0.71 & 0.99 & 1.02 & 0.98 \\
\hline 0.94 & 2770.6 & 1870.8 & 307.0 & 4.7 & 588.1 & 2177.8 & 592.8 & 1.01 & 1.02 & 0.93 & 0.85 & 0.99 & 1.01 & 0.99 \\
\hline 0.95 & 2752.7 & 1826.1 & 328.7 & 5.5 & 592.3 & 2154.8 & 597.9 & 1.00 & 1.00 & 1.00 & 1.00 & 1.00 & 1.00 & 1.00 \\
\hline 0.96 & 2735.0 & 1782.8 & 349.3 & 6.4 & 596.5 & 2132.1 & 602.9 & 0.99 & 0.98 & 1.06 & 1.16 & 1.01 & 0.99 & 1.01 \\
\hline 0.97 & 2717.6 & 1740.9 & 368.8 & 7.3 & 600.6 & 2109.7 & 607.9 & 0.99 & 0.95 & 1.12 & 1.33 & 1.01 & 0.98 & 1.02 \\
\hline 0.98 & 2700.3 & 1700.2 & 387.3 & 8.3 & 604.6 & 2087.5 & 612.8 & 0.98 & 0.93 & 1.18 & 1.51 & 1.02 & 0.97 & 1.02 \\
\hline 0.99 & 2683.3 & 1660.8 & 404.8 & 9.2 & 608.5 & 2065.6 & 617.7 & 0.97 & 0.91 & 1.23 & 1.67 & 1.03 & 0.96 & 1.03 \\
\hline 1.00 & 2666.4 & 1622.6 & 421.3 & 10.3 & 612.3 & 2043.9 & 622.5 & 0.97 & 0.89 & 1.28 & 1.87 & 1.03 & 0.95 & 1.04 \\
\hline 1.20 & 2366.5 & 1053.5 & 609.2 & 33.0 & 670.8 & 1662.7 & 703.8 & 0.86 & 0.58 & 1.85 & 6.00 & 1.13 & 0.77 & 1.18 \\
\hline 1.40 & 2124.7 & 721.6 & 647.1 & 54.4 & 701.6 & 1368.7 & 756.0 & 0.77 & 0.40 & 1.97 & 9.89 & 1.18 & 0.64 & 1.26 \\
\hline 1.60 & 1926.3 & 515.3 & 626.4 & 71.4 & 713.2 & 1141.7 & 784.6 & 0.70 & 0.28 & 1.91 & 12.98 & 1.20 & 0.53 & 1.31 \\
\hline 1.80 & 1761.0 & 380.6 & 583.9 & 84.0 & 712.5 & 964.6 & 796.4 & 0.64 & 0.21 & 1.78 & 15.27 & 1.20 & 0.45 & 1.33 \\
\hline 2.00 & 1621.3 & 289.0 & 535.4 & 93.0 & 703.9 & 824.4 & 796.9 & 0.59 & 0.16 & 1.63 & 16.91 & 1.19 & 0.38 & 1.33 \\
\hline 2.20 & 1501.9 & 224.5 & 487.5 & 99.2 & 690.6 & 712.0 & 789.8 & 0.55 & 0.12 & 1.48 & 18.04 & 1.17 & 0.33 & 1.32 \\
\hline 2.40 & 1398.6 & 177.9 & 442.9 & 103.4 & 674.5 & 620.8 & 777.9 & 0.51 & 0.10 & 1.35 & 18.80 & 1.14 & 0.29 & 1.30 \\
\hline 2.60 & 1308.5 & 143.3 & 402.4 & 106.0 & 656.8 & 545.7 & 762.8 & 0.48 & 0.08 & 1.22 & 19.27 & 1.11 & 0.25 & 1.28 \\
\hline 2.80 & 1229.2 & 117.1 & 366.2 & 107.4 & 638.5 & 483.3 & 745.9 & 0.45 & 0.06 & 1.11 & 19.53 & 1.08 & 0.22 & 1.25 \\
\hline 3.00 & 1158.9 & 96.9 & 334.0 & 107.9 & 620.1 & 430.9 & 728.0 & 0.42 & 0.05 & 1.02 & 19.62 & 1.05 & 0.20 & 1.22 \\
\hline 4.00 & 900.7 & 43.6 & 219.4 & 103.7 & 534.0 & 263.0 & 637.7 & 0.33 & 0.02 & 0.67 & 18.85 & 0.90 & 0.12 & 1.07 \\
\hline 5.00 & 736.3 & 23.2 & 153.6 & 95.5 & 464.0 & 176.8 & 559.5 & 0.27 & 0.01 & 0.47 & 17.36 & 0.78 & 0.08 & 0.94 \\
\hline 6.00 & 622.6 & 13.8 & 113.1 & 87.2 & 408.5 & 126.9 & 495.7 & 0.23 & 0.01 & 0.34 & 15.85 & 0.69 & 0.06 & 0.83 \\
\hline 7.00 & 539.3 & 8.8 & 86.6 & 79.7 & 364.1 & 95.4 & 443.8 & 0.20 & 0.00 & 0.26 & 14.49 & 0.61 & 0.04 & 0.74 \\
\hline 8.00 & 475.6 & 6.0 & 68.4 & 73.1 & 328.1 & 74.4 & 401.2 & 0.17 & 0.00 & 0.21 & 13.29 & 0.55 & 0.03 & 0.67 \\
\hline 9.00 & 425.3 & 4.3 & 55.3 & 67.4 & 298.3 & 59.6 & 365.8 & 0.15 & 0.00 & 0.17 & 12.25 & 0.50 & 0.03 & 0.61 \\
\hline 10.00 & 384.7 & 3.1 & 45.7 & 62.5 & 273.4 & 48.8 & 335.9 & 0.14 & 0.00 & 0.14 & 11.36 & 0.46 & 0.02 & 0.56 \\
\hline
\end{tabular}


The evolutions of normalized activity and normalized surface site concentrations (all sites (Fig.6a), corner (Fig.6b), edge (Fig.6c), face (100) (Fig.6d), face (111) (Fig.6e), corner + edge (Fig.6f) and all faces (Fig.6g)) versus the particle size are presented in Fig.6. The best correlation between the experimental values of PDH activity and the surface site concentration predicted by the model is obtained for the [corner + edge] concentration (Fig.6f). The evolution of initial propane activity obtained with the four studied catalysts scales linearly with the [corner + edge] surface site concentrations, with an interception to zero (see Fig.6h). This result clearly evidences that the initial activity for PDH reaction is directly correlated with the quantity of corner + edge sites. The findings deduced from our approach based on a geometric model is in perfect accordance with the DFT results of Zhu et al. [18] which demonstrated that the catalyst with a higher fraction of $\mathrm{Pt}(211)$ on the surface (associated to corner + edge) would give rise to a lower dehydrogenation activation energy and thus to a higher activity. 

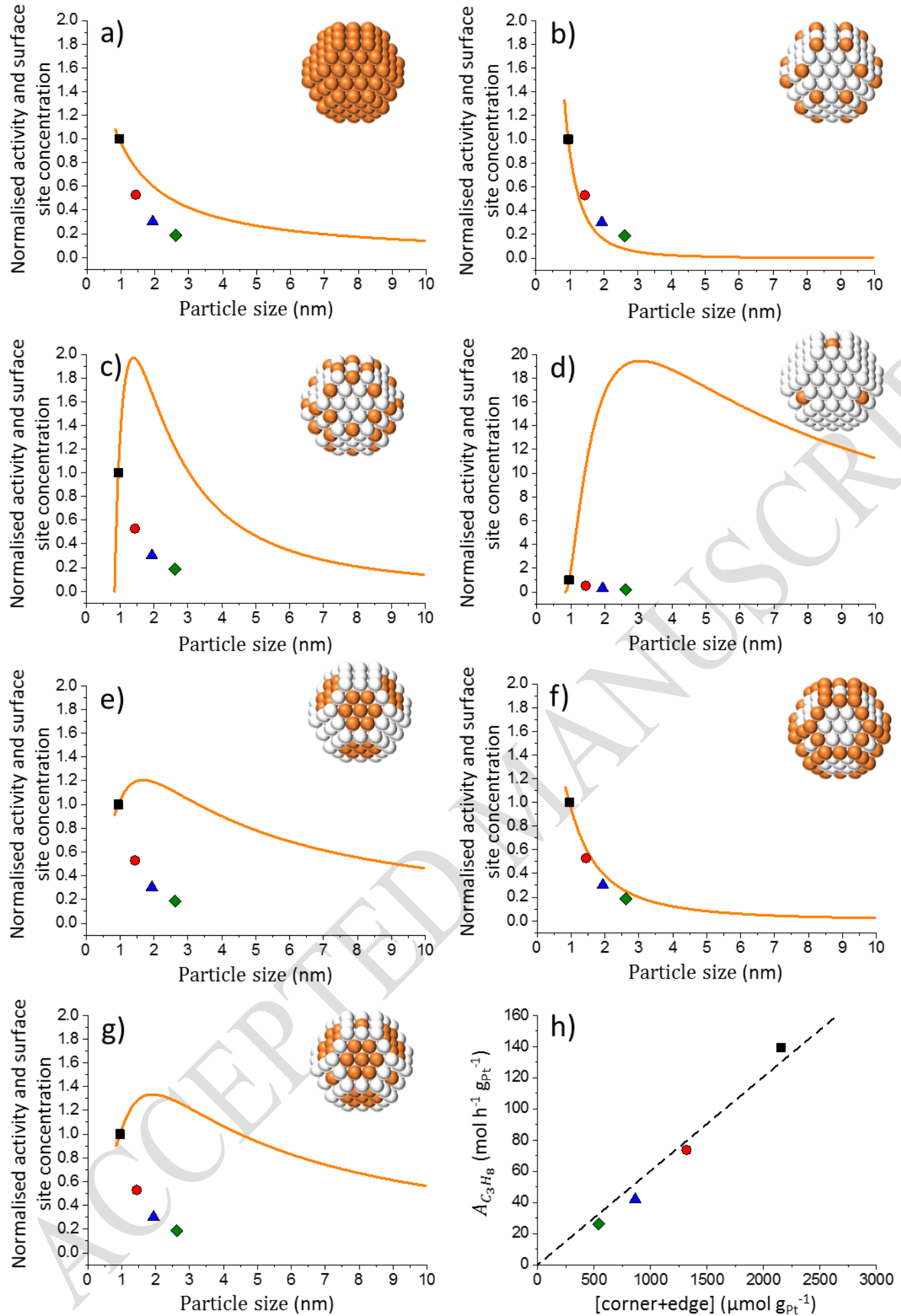

Fig.6. Evolution of the normalized activity for PDH (symbols) and normalized surface site concentrations (orange curves) versus the particle size: a) all sites; b) corner; c) edge; d) face (100); e) face (111); f) corner + edge and g) all faces; h) Evolution of the initial activity versus corner + edge surface site concentration. Square: $\mathrm{Pt} / \mathrm{Al}_{2} \mathrm{O}_{3}(\mathrm{RO})$ used as reference; circle: $\mathrm{Pt} / \mathrm{Al}_{2} \mathrm{O}_{3}(\mathrm{R} 1)$; triangle: $\mathrm{Pt} / \mathrm{Al}_{2} \mathrm{O}_{3}(\mathrm{R} 2)$; lozenge: $\mathrm{Pt} / \mathrm{Al}_{2} \mathrm{O}_{3}(\mathrm{R} 3)$ ). Orange curves: results predicted with the model by using the particle size value of $\mathrm{Pt} / \mathrm{Al}_{2} \mathrm{O}_{3}(\mathrm{RO})(\bar{d}=0.95 \mathrm{~nm})$ for the normalization. 
In order to validate the present geometric approach on other fcc metals and/or other reactions, it is necessary to find studies of the literature giving us access to values of catalytic activity, particle size and precise knowledge of the nature of the active sites for structure-sensitive reactions. So, we extracted numerous data from literature $[21,26,27,28]$, listed in Table S.1 (in Supporting Information), and confronted them with the values determined from our model. Figs.S.3-6 displayed the normalized catalytic activities calculated from these data as function of the particle sizes for the four following respective reactions: ethane hydrogenolysis over $\mathrm{Pt} / \mathrm{SBA}-15$, water gas shift (denoted WGS) over $\mathrm{Au} / \mathrm{Al}_{2} \mathrm{O}_{3}$, methane steam reforming (denoted $\mathrm{MSR}$ ) over $\mathrm{Rh} / \mathrm{ZrO}_{2}$, and ethanol steam reforming (denoted ESR) over Co/C. For all reactions, the normalized activity decreases with the increase of particle size. Theoretical calculations by DFT over Pt(211) and Pt(111) surfaces supported the observed structure sensitivity for ethane hydrogenolysis on Pt catalysts, since the results of Watwe et al. [29] suggested that the active sites are defect sites such as the step edge of Pt(211). In the case of the WGS reaction, DFT calculations performed by Shekhar et al. [26] suggested that both corner and low-coordinated perimeter (atoms in contact with the support) sites are active sites on an $\mathrm{Au} / \mathrm{Al}_{2} \mathrm{O}_{3}$ catalyst. The DFT results of Zhao et al. [30] obtained on $\mathrm{Au} / \mathrm{MgO}$ catalysts clearly showed the critical role played by the metal/oxide interface in WGS catalysis (the effect of the support is not taken into account in our model). These authors observed that corner sites were at least of similar activity to the perimeter sites. For the MSR reaction over $\mathrm{Rh} / \mathrm{ZrO}_{2}$, Jones et al. [27] proposed, according to their DFT theoretical results, that the reactivity is dominated by steps and corners of the Rh particle. Finally, da Silva et al. [28] proposed, with the help of geometric model, that the effect of the cobalt particle size in the ESR reaction was attributed to the increasing fraction of edge and corner surface sites with decreasing size. For the four involved reactions, the evolution of the normalized surface site concentration displaying the best agreement with the normalized activity was gathered in Fig.7. Results clearly show that our geometric model accurately predicts the structure-sensitive dependence determined by theoretical approaches in each case, i.e. an activity directly proportional to the concentration of (i) edges for ethane hydrogenolysis on Pt catalysts as in ref [29] (Fig.7a), (ii) corners for WGS reaction on Au catalysts as in ref [26], (iii) corners + edges for MSR on Rh catalysts as in ref [27], (iv) edges for ESR on Co catalysts. In this last case, the correlation with the concentration of edge sites appears more favorable than the one with the corner + edge sites (Fig.S.6c compared to Fig.S.6f, $R^{2}$ correlation 
coefficient equal to 0.9668 versus 0.9571 , respectively). Nevertheless, the theoretical results obtained in ref [28] aren't challenged for all that.
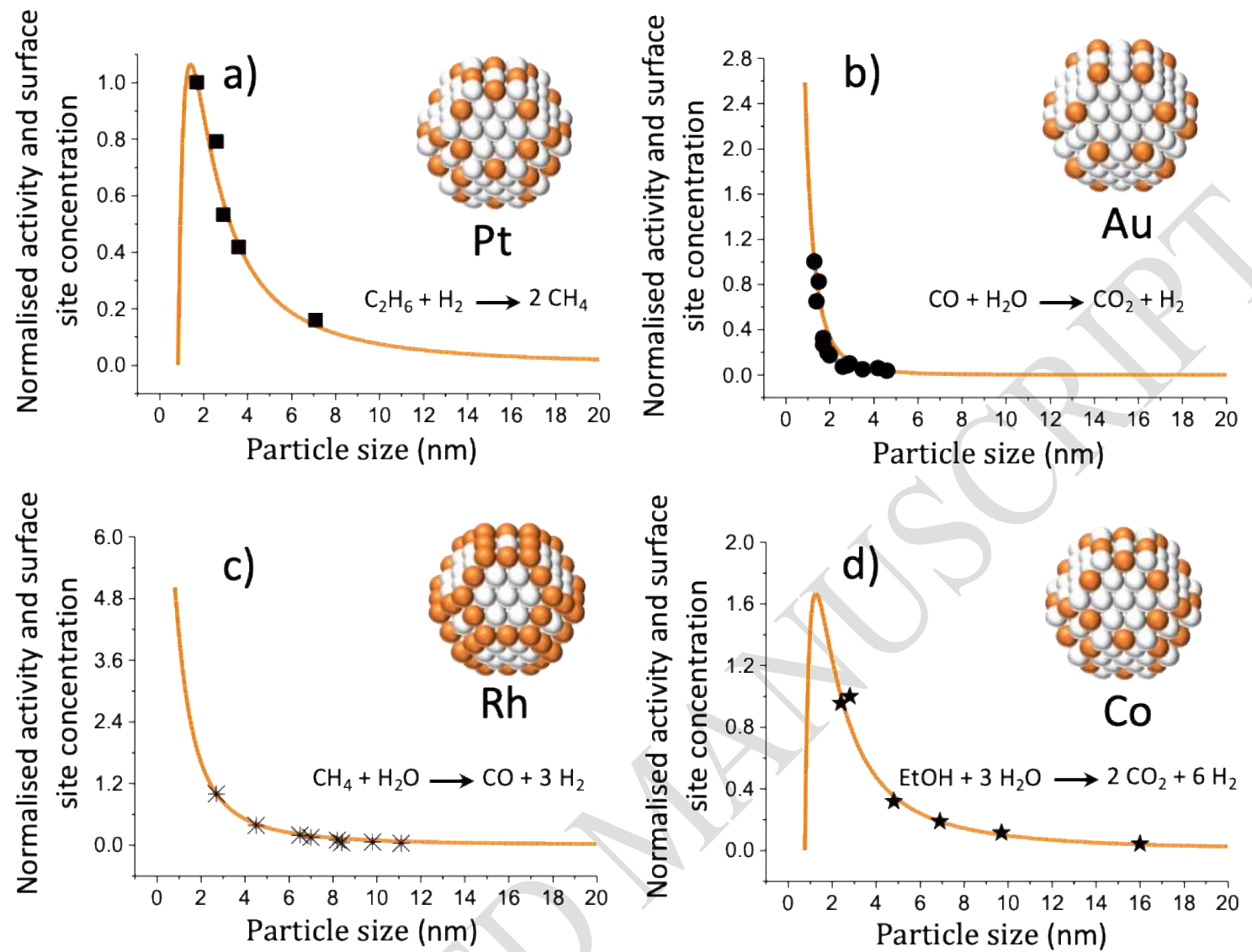

Fig.7. Evolution of the normalized activities calculated from literature data (square, circle, cross, star) and normalized surface site concentrations (orange curves) versus the particle size for: a) ethane hydrogenolysis on $\mathrm{Pt} / \mathrm{SBA}-15$ [21]; b) water gas shift on $\mathrm{Au} / \mathrm{Al}_{2} \mathrm{O}_{3}$ [26]; c) methane steam reforming on $\mathrm{Rh} / \mathrm{ZrO}_{2}$ [27] and d) ethanol steam reforming on $\mathrm{Co} / \mathrm{C}[28]$. Orange curves: results predicted with the model by using the following particle size values for the normalization: $\overline{\mathrm{d}}=1.7 \mathrm{~nm}$ for Pt/SBA-15, $\overline{\mathrm{d}}=1.3 \mathrm{~nm}$ for $\mathrm{Au} / \mathrm{Al}_{2} \mathrm{O}_{3}, \overline{\mathrm{d}}=2.7 \mathrm{~nm}$ for $\mathrm{Rh} / \mathrm{ZrO}_{2}$ and $\overline{\mathrm{d}}=2.4 \mathrm{~nm}$ for $\mathrm{Co} / \mathrm{C}$ (with $\mathrm{d}_{\mathrm{Pt}}=0.279 \mathrm{~nm}, \mathrm{MPt}_{\mathrm{Pt}}=195.08 \mathrm{~g} \mathrm{~mol}^{-1}, \mathrm{~d}_{\mathrm{Au}}=0.288 \mathrm{~nm}, \mathrm{M}_{\mathrm{Au}}=196.97 \mathrm{~g} \mathrm{~mol}^{-1}, \mathrm{~d}_{\mathrm{Rh}}=0.269$ $\mathrm{nm}, \mathrm{M}_{\mathrm{Rh}}=102.91 \mathrm{~g} \mathrm{~mol}^{-1}, \mathrm{~d}_{\mathrm{Co}}=0.250 \mathrm{~nm}$ and $\left.M_{\mathrm{Co}_{0}}=58.933 \mathrm{~g} \mathrm{~mol}^{-1}\right)$.

\section{Conclusion}

To explain the particle size effect on metal catalyzed reaction, a geometric model (based on truncated octahedron shape) was developed to allow the quantification of surface site concentrations (corner, edge, face (100) and face (111)) for any fcc metal particle size. In the case of Pt, the model predicted that the effect of the particle size on the surface site concentration distribution was the most significant for particle sizes lower than $3.04 \mathrm{~nm}$.

In order to validate the geometric model, a series of $\mathrm{Pt} / \mathrm{Al}_{2} \mathrm{O}_{3}$ catalysts was prepared using a specific preparation technique, the refilling method, developed in our laboratory since 1978, 
and allowing to easily and precisely control the growing of supported metal nanoparticles starting from a parent catalyst. The propane dehydrogenation activity was investigated on this $\mathrm{Pt} / \mathrm{Al}_{2} \mathrm{O}_{3}$ catalysts series, with sizes ranging from 0.95 to $2.62 \mathrm{~nm}$. The catalytic experiments showed that the initial activity and the initial $\mathrm{TOF}_{\mathrm{C}_{3} \mathrm{H}_{8}}$ decreased with the increase of particle size, indicating that propane dehydrogenation is a structure sensitive reaction. Comparing the evolution of the normalized initial activity with the different normalized surface site concentrations (calculated from the geometric model), it was shown that the active sites corresponded to the combination of corner and edge Pt atoms (in accordance with the DFT results of Zhu et al. [18]). Moreover, the model has subsequently been confronted with numerous data extracted from literature (involving different fcc metal and reactions) and it has accurately predicted the structure-sensitive dependence and the nature of active sites determined by DFT approaches.

To conclude, the developed model based on surface site concentration is a powerful predictive tool for understanding the structure-activity relationship of fcc metal catalysts.

\section{Acknowledgement}

The authors acknowledge financial support from the European Regional Development Fund (ERDF) and Région Nouvelle Aquitaine. This work pertains to the French Government program «Investissements d'Avenir» (EUR INTREE, reference ANR-18-EURE-0010). A. Le Valant thanks C. Comminges (IC2MP, France), D. Duprez (IC2MP, France) and S. Thomas (ICPEES, France) for scientific discussions.

\section{References}

[1]: J. A. Dumesic, G. W. Huber, M. Boudart, Principles of Heterogeneous Catalysis, H. Knözinger, F. Schüth, J. Weitkamp (Eds.), Handbook of Heterogeneous Catalysis, Wiley-VCH, (2008) 1-15. [2]: H. Nakatsuji, Y. Matsuzaki, T. Yonezawa, Abinitio theoretical study on the reactions of a hydrogen molecule with small platinum clusters: A model for chemisorption on a Pt surface, J. Chem. Phys. 88 (1988) 5759-5769.

[3]: B. Yang, Q. Lu, Y. Wang, L. Zhuang, J. Lu, P. Liu, J. Wang, R. Wang, Simple and Low-Cost Preparation Method for Highly Dispersed PtRu/C Catalysts. Chem. Mater. 15 (2003) 3552-3557.

[4]: Z. Q. Tian, F. Y. Xie, P. K. Shen, Preparation of high loading Pt supported on carbon by onsite reduction. J. Mater. Sci. 39 (2004) 1507-1509.

[5]: G. A Somorjai, The surface science of heterogeneous catalysis, Surf. Sci., 299-300 (1994) 849-866. 
[6]: B. C. Gates, Models of metal catalysts: beyond single crystals, Top. Catal., 14 (2001) $173-$ 180.

[7]: G. A. Somorjai, Y. G. Borodko, Research in Nanosciences - Great Opportunity for Catalysis Science, Catal. Letters 76 (2001) 1-5.

[8]: H. S. Taylor, Fourth Report of the Committee on Contact Catalysis, J. Phys. Chem. 30 (1926) 145-171.

[9]: R. Van Hardeveld, F. Hartog, The statistics of surface atoms and surface sites on metal crystals, Surf. Sci. 15 (1969) 189-230.

[10]: M. Boudart, Catalysis by supported metals, D.D. Eley, H. Pines, P. B. Weisz (Eds.), Advances in Catalysis, Academic Press, 20 (1969) 153-166.

[11]: V. R. Stamenkovic, B. Fowler, B. S. Mun, G. Wang, P. N. Ross, C. A. Lucas, N. M. Marković, Improved Oxygen Reduction Activity on $\mathrm{Pt}_{3} \mathrm{Ni}(111)$ via Increased Surface Site Availability, Science 315 (2007) 493-497.

[12]: S. Kuld, M. Thorhauge, H. Falsig, C. F. Elkjær, S. Helveg, I. Chorkendorff, J. Sehested, Quantifying the promotion of Cu catalysts by ZnO for methanol synthesis, Science 352 (2016) 969-974.

[13]: F. Abild-Pedersen, J. Greeley, F. Studt, J. Rossmeisl, T. R. Munter, P. G. Moses, E. Skúlason, T. Bligaard, J. K. Nørskov, Scaling Properties of Adsorption Energies for Hydrogen-Containing Molecules on Transition-Metal Surfaces, Phys. Rev. Lett. 99 (2007) 016105.

[14]: F. Calle-Vallejo, D. Loffreda, M. T. M. Koper, P. Sautet, Introducing structural sensitivity into adsorption-energy scaling relations by means of coordination numbers, Nature Chemistry 7 (2015) 403-410.

[15]: F. Calle-Vallejo, J. Tymoczko, V. Colic, Q. H. Vu, M. D. Pohl, K. Morgenstern, D. Loffreda, P. Sautet, W. Schuhmann, A. S. Bandarenka, Finding optimal surface sites on heterogeneous catalysts by counting nearest neighbors, Science 350 (2015) 185-189.

[16]: J.J.H.B. Sattler, J. Ruiz-Martinez, E. Santillan-Jimenez, B.M. Weckhuysen, Catalytic Dehydrogenation of Light Alkanes on Metals and Metal Oxides, Chem. Rev. 114 (2014) 1061310653.

[17]: M. S. Kumar, D. Chen, J.C. Walmsley, A. Holmen, Dehydrogenation of propane over PtSBA-15: Effect of Pt particle size, Catal. Commun. 9 (2008) 747-750.

[18]: J. Zhu, M-L. Yang, Y. Yu, Y-A. Zhu, Z-J. Sui, X-G. Zhou, A. Holmen, D. Chen, Size-Dependent Reaction Mechanism and Kinetics for Propane Dehydrogenation over Pt Catalysts, ACS Catalysis 5 (2015) 6310-6319.

[19]: W. Zhang, H. Wang, J. Jiang, Z. Sui, Y. Zhu, D. Chen, X. Zhou, Size Dependence of Pt Catalysts for Propane Dehydrogenation: from Atomically Dispersed to Nanoparticles, ACS Catalysis 10 (2020) 12932-12942.

[20]: J.C. Menezo, M.F. Denanot, S. Peyrovi, J. Barbier, A "refilling" technique for catalyst particle modification, Appl. Catal. 15 (1985) 353-356.

[21]: R. M. Rioux, H. Song, J. D. Hoefelmeyer, P. Yang, G. A. Somorjai, High-Surface-Area Catalyst Design: Synthesis, Characterization, and Reaction Studies of Platinum Nanoparticles in Mesoporous SBA-15 Silica, J. Phys. Chem. B 109 (2005) 2192-2202.

[22]: A. Le Valant, C. Comminges, F. Can, K. Thomas, M. Houalla, F. Epron, Platinum supported catalysts: predictive $\mathrm{CO}$ and $\mathrm{H} 2$ chemisorption by a statistical cuboctahedron cluster model, J. Phys. Chem. C 120 (2016) 26374-26385.

[23]: A. Le Valant, F. Drault, C. Maleix, C. Comminges, R. Beauchet, Y. Batonneau, L. Pirault-Roy, C. Especel, F. Epron, Effect of the metallic particle size of supported Pt catalysts on methylcyclopentane hydrogenolysis: Understanding of the ring opening products distribution by a geometric approach, J. Catal. 367 (2018) 234-243. 
[24]: N. E. Şahin, C. Comminges, A. Le Valant, J. Kiener, J. Parmentier, T. W. Napporn, G. Melinte, O. Ersen, K. B. Kokoh, One-Pot Soft-Template Synthesis of Nanostructured Copper-Supported Mesoporous Carbon FDU-15 Electrocatalysts for Efficient CO2 Reduction, ChemPhysChem 19 (2018) 1371-1381.

[25]: J. Barbier, A. Morales, R. Maurel, Activity of Metal-Catalysts. 7. Study of Ethane Hydrogenolysis on Platinum-Alumina Catalysts with Different Degrees of Dispersion, Bull. Soc. Chim. Fr. 1-2 (1978) 131-135.

[26]: M. Shekhar, J. Wang, W. S. Lee, W. D. Williams, S. M. Kim, E. A. Stach, J. T. Miller, W. N. Delgass, F. H. Ribeiro, Size and Support Effects for the Water-Gas Shift Catalysis over Gold Nanoparticles Supported on Model Al2O3 and TiO2, J. Am. Chem. Soc. 134 (2012) 4700-4708. [27]: G. Jones, J. G. Jakobsen, S. S. Shim, J. Kleis, M. P. Andersson, J. Rossmeisl, F. AbildPedersen, T. Bligaard, S. Helveg, B. Hinnemann, J. R. Rostrup-Nielsen, I. Chorkendorff, J. Sehested, J. K. Nørskov, First principles calculations and experimental insight into methane steam reforming over transition metal catalysts, J. Catal. 259 (2008) 147-160.

[28]: A. L. M. da Silva a, J. P. den Breejen, L. V. Mattos, J. H. Bitter, K. P. de Jong, F. B. Noronha, Cobalt particle size effects on catalytic performance for ethanol steam reforming - Smaller is better, J. Catal. 318 (2014) 67-74.

[29]: R. M. Watwe, R. D. Cortright, J. K. Nørskov, J. A. Dumesic, Theoretical Studies of Stability and Reactivity of C2 Hydrocarbon Species on Pt Clusters, J. Phys. Chem. B 104 (2000) 22992310.

[30]: Z. J. Zhao, Z. Li, Y. Cui, H. Zhu, W. F. Schneider, W. N. Delgass, F. Ribeiro, J. Greeley, Importance of metal-oxide interfaces in heterogeneous catalysis: A combined DFT, microkinetic, and experimental study of water-gas shift on Au/MgO, J. Catal. 345 (2017) 157169. 


\section{Supporting Information}

\section{Description of supported metal structure sensitivity by a geometric approach}

Anthony Le Valant*, Samuel Bouchet, Alexandre Van Assche, Catherine Especel, Florence Epron

Institut de chimie des milieux et des matériaux de Poitiers (IC2MP), Université de Poitiers, UMR 7285 CNRS, 4, rue Michel Brunet, 86073 Poitiers cedex 9, France

* Corresponding author.

E-mail address: anthony.le.valant@univ-poitiers.fr

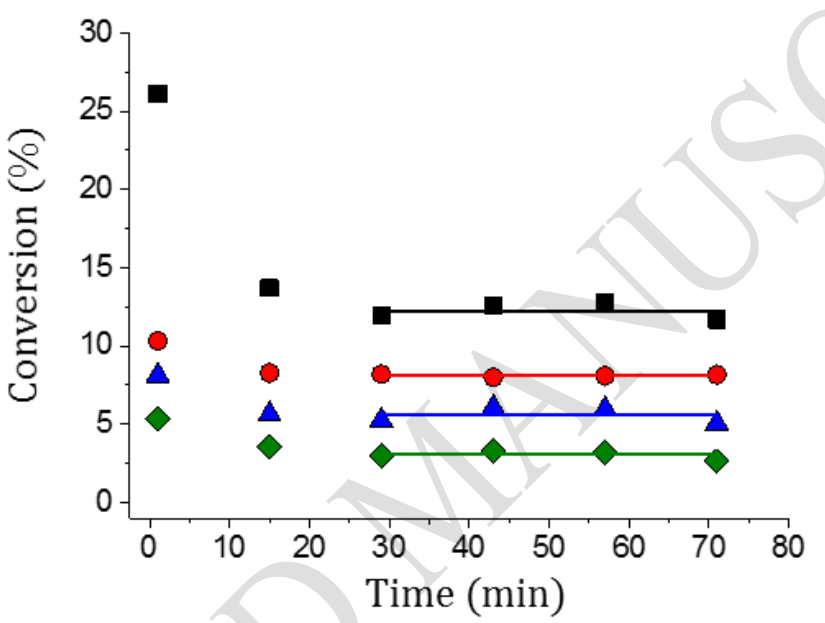

Fig.S.1. Evolution of the propane conversion in function of the time of stream (square: $\mathrm{Pt} / \mathrm{Al}_{2} \mathrm{O}_{3}(\mathrm{RO})$; circle: $\mathrm{Pt} / \mathrm{Al}_{2} \mathrm{O}_{3}(\mathrm{R} 1)$; triangle: $\mathrm{Pt} / \mathrm{Al}_{2} \mathrm{O}_{3}(\mathrm{R} 2)$; lozenge: $\mathrm{Pt} / \mathrm{Al}_{2} \mathrm{O}_{3}(\mathrm{R} 3)$ ). 

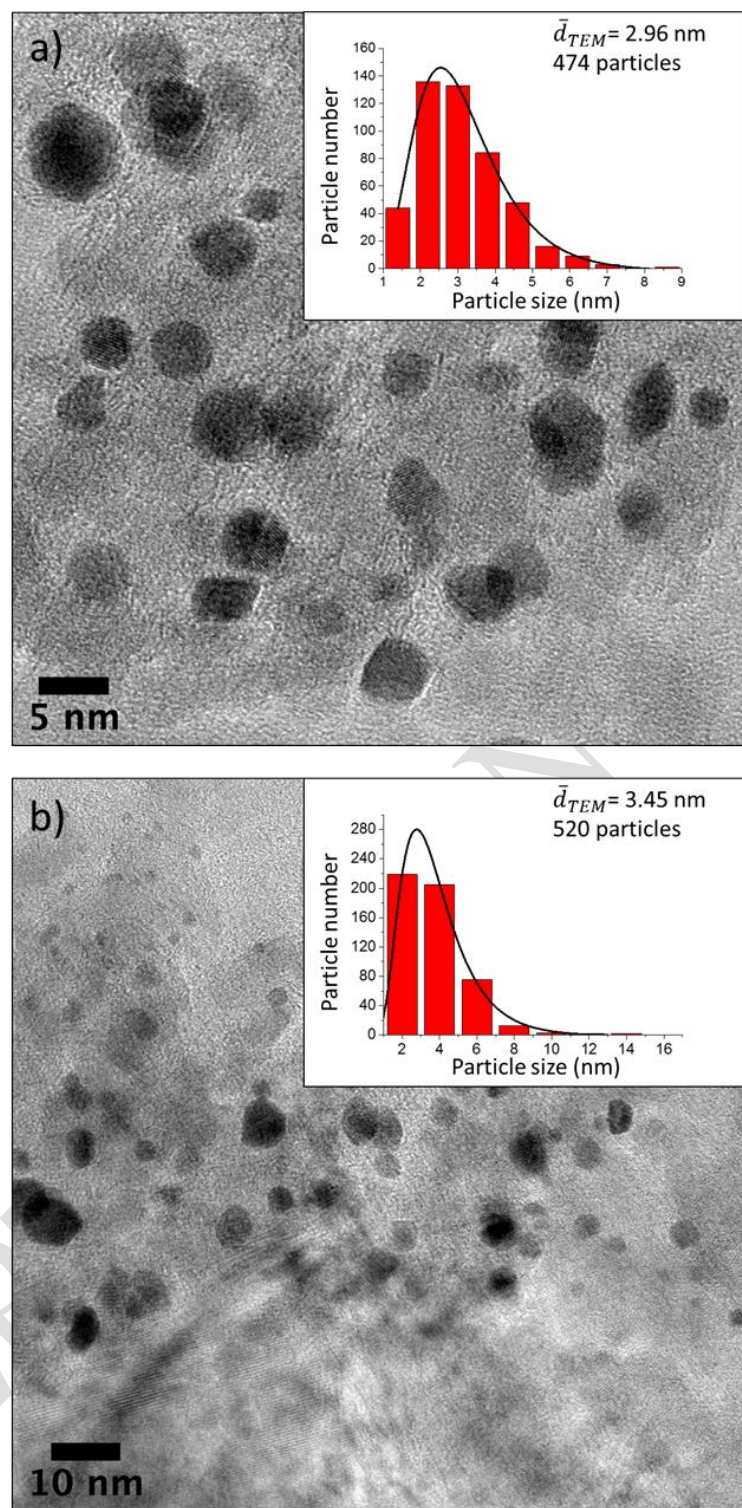

Fig.S.2. TEM images and particle size distributions of Pt catalysts after $\mathrm{PDH}$ reaction (a: $\mathrm{Pt} / \mathrm{Al}_{2} \mathrm{O}_{3}(\mathrm{RO})$ and b: $\left.\mathrm{Pt} / \mathrm{Al}_{2} \mathrm{O}_{3}(\mathrm{R} 3)\right)$. 
Table S.1. Literature data used to calculate normalized activities according to the geometric model described in the present work (values highlighted in gray represent reference values used for the model, i.e. the particle size and activity of the reference catalyst for each series).

\begin{tabular}{|c|c|c|c|c|c|c|c|c|c|c|c|c|}
\hline \multicolumn{3}{|c|}{ Catalyst } & \multicolumn{2}{|c|}{ Characterization } & \multicolumn{4}{|c|}{ Activity in Ref. } & \multirow{2}{*}{ Reaction } & \multirow{2}{*}{ Ref. } & \multicolumn{2}{|c|}{ Calculated data in this work } \\
\hline M & support & $\%$ wt & $\underset{(\mathrm{nm})}{\overline{\boldsymbol{d}}}$ & $\begin{array}{c}D \\
(\%)\end{array}$ & $\begin{array}{l}\text { TOF } \\
\left(\mathrm{s}^{-1}\right)\end{array}$ & $\begin{array}{c}\text { Activity } \\
\left(\mu \mathrm{mol} \mathrm{g}^{-1} \mathrm{~s}^{-1}\right)\end{array}$ & $\begin{array}{c}\text { Activity } \\
\left(\mathrm{mol} \mathrm{mol}_{\left.\mathrm{M}^{-1} \mathrm{~s}^{-1}\right)}\right.\end{array}$ & $\begin{array}{c}\text { Activity } \\
\left(\mathrm{mol} \mathrm{g}_{\left.\mathrm{M}^{-1} \mathrm{~s}^{-1}\right)}\right.\end{array}$ & & & $\begin{array}{c}\text { Activity } \\
\left(\mathrm{mmol} \mathrm{gM}^{-1} \mathrm{~s}^{-1}\right)\end{array}$ & $\begin{array}{c}\text { Normalised } \\
\text { activity }\end{array}$ \\
\hline \multirow{5}{*}{$\mathrm{Pt}$} & \multirow{5}{*}{ SBA-15 } & 0.73 & 1.7 & - & - & 0.159 & - & - & \multirow{5}{*}{$\begin{array}{c}\text { Ethane } \\
\text { hydrogenolysis }\end{array}$} & \multirow{5}{*}[1]{} & 0.022 & 1.00 \\
\hline & & 0.90 & 2.6 & - & - & 0.155 & - & - & & & 0.017 & 0.79 \\
\hline & & 0.95 & 2.9 & - & - & 0.110 & - & - & & & 0.012 & 0.53 \\
\hline & & 1.0 & 3.6 & - & - & 0.091 & - & - & & & 0.009 & 0.42 \\
\hline & & 1.01 & 7.1 & - & - & 0.035 & - & - & & & 0.003 & 0.16 \\
\hline \multirow{13}{*}{$\mathrm{Au}$} & \multirow{13}{*}{$\mathrm{Al}_{2} \mathrm{O}_{3}$} & 0.7 & 1.3 & - & - & & $17.0 \times 10^{-3}$ & - & \multirow{13}{*}{ Water gas shift } & \multirow{13}{*}{ [2] } & $8.6 \times 10^{-5}$ & 1.00 \\
\hline & & 0.7 & 1.5 & - & - & - & $14.0 \times 10^{-3}$ & - & & & $7.1 \times 10^{-5}$ & 0.82 \\
\hline & & 0.7 & 1.4 & - & - & - & $11.0 \times 10^{-3}$ & - & & & $5.6 \times 10^{-5}$ & 0.65 \\
\hline & & 0.7 & 1.9 & - & - & & $3.3 \times 10^{-3}$ & - & & & $1.7 \times 10^{-5}$ & 0.19 \\
\hline & & 0.7 & 2.9 & - & - & - & $1.7 \times 10^{-3}$ & - & & & $0.9 \times 10^{-5}$ & 0.10 \\
\hline & & 0.7 & 4.2 & - & - & - & $1.0 \times 10^{-3}$ & - & & & $0.5 \times 10^{-5}$ & 0.06 \\
\hline & & 1.4 & 1.7 & - & - & - & $5.5 \times 10^{-3}$ & - & & & $2.8 \times 10^{-5}$ & 0.32 \\
\hline & & 1.4 & 1.7 & - & - & - & $4.5 \times 10^{-3}$ & - & & & $2.3 \times 10^{-5}$ & 0.26 \\
\hline & & 1.3 & 2 & - & - & - & $2.9 \times 10^{-3}$ & - & & & $1.5 \times 10^{-5}$ & 0.17 \\
\hline & & 1.4 & 2.6 & - & - & - & $1.2 \times 10^{-3}$ & - & & & $0.6 \times 10^{-5}$ & 0.07 \\
\hline & & 1.4 & 2.8 & - & - & - & $1.4 \times 10^{-3}$ & - & & & $0.7 \times 10^{-5}$ & 0.08 \\
\hline & & 1.4 & 3.5 & - & - & - & $0.8 \times 10^{-3}$ & - & & & $0.4 \times 10^{-5}$ & 0.05 \\
\hline & & 1.4 & 4.6 & - & - & - & $0.6 \times 10^{-3}$ & -2 & & & $0.3 \times 10^{-5}$ & 0.04 \\
\hline \multirow{8}{*}{$\mathrm{Rh}$} & \multirow{8}{*}{$\mathrm{ZrO}_{2}$} & 1 & 2.7 & 32.3 & 12.5 & - & - & - & \multirow{8}{*}{$\begin{array}{l}\text { Methane steam } \\
\text { reforming }\end{array}$} & \multirow{8}{*}{ [3] } & 39.2 & 1.00 \\
\hline & & 1 & 8.4 & 10.6 & 1.8 & - & - & - & & & 1.9 & 0.05 \\
\hline & & 5 & 4.5 & 21 & 7.4 & - & - & - & & & 15.1 & 0.38 \\
\hline & & 5 & 8.2 & 11 & 3.6 & - & - & - & & & 3.8 & 0.10 \\
\hline & & 5 & 6.5 & 12.7 & 6.2 & - & $-\infty x^{2}$ & - & & & 7.7 & 0.20 \\
\hline & & 5 & 7 & 12.8 & 4.7 & - & $-\quad$ & - & & & 5.8 & 0.15 \\
\hline & & 5 & 9.8 & 9.5 & 2.5 & - & - & - & & & 2.3 & 0.06 \\
\hline & & 5 & 11.1 & 7.6 & 2 & - & - & - & & & 1.5 & 0.04 \\
\hline \multirow{6}{*}{ Co } & \multirow{6}{*}{$\begin{array}{c}\text { Carbon } \\
\text { nanofibers }\end{array}$} & 1 & 2.4 & - & - & - & - & $66 \times 10^{-3}$ & \multirow{6}{*}{$\begin{array}{l}\text { Ethanol steam } \\
\text { reforming }\end{array}$} & \multirow{6}{*}[4]{} & 66 & 1.00 \\
\hline & & 0.9 & 2.8 & - & - & -1 & - & $69 \times 10^{-3}$ & & & 69 & 1.05 \\
\hline & & 3.5 & 4.8 & - & - & - & - & $22 \times 10^{-3}$ & & & 22 & 0.33 \\
\hline & & 6.0 & 6.9 & - & - & - & - & $13 \times 10^{-3}$ & & & 13 & 0.20 \\
\hline & & 9.7 & 9.7 & - & - & - & - & $8 \times 10^{-3}$ & & & 8 & 0.12 \\
\hline & & 22 & 16 & - & -3 & - & - & $3 \times 10^{-3}$ & & & 3 & 0.05 \\
\hline
\end{tabular}



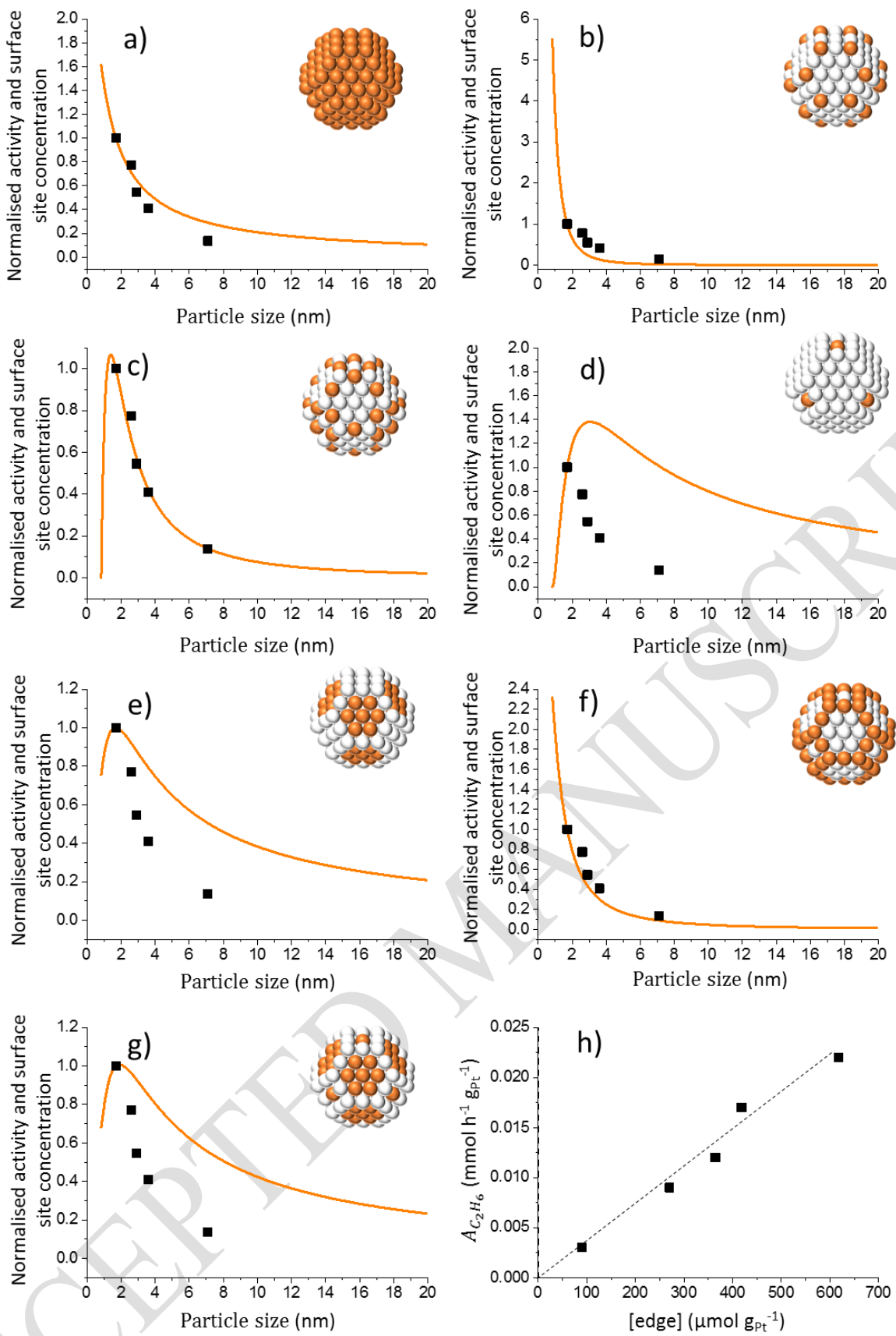

Fig.S.3. Evolution of the normalized ethane hydrogenolysis activity of Pt/SBA-15 catalysts (square, [1]) and normalized surface site concentrations (orange curves) versus the particle size: a) all sites; b) corner; c) edge; d) face (100); e) face (111); f) corner + edge and g) all faces; h) Evolution of the activity versus edge surface site concentration. Orange curves: results predicted with the model by using the particle size value $\bar{d}=1.7 \mathrm{~nm}$ for the normalization (with $\mathrm{d}_{\mathrm{pt}}=0.279 \mathrm{~nm}, \mathrm{Mpt}_{\mathrm{Pt}}=195.08 \mathrm{~g} \mathrm{~mol}^{-1}$ ). 

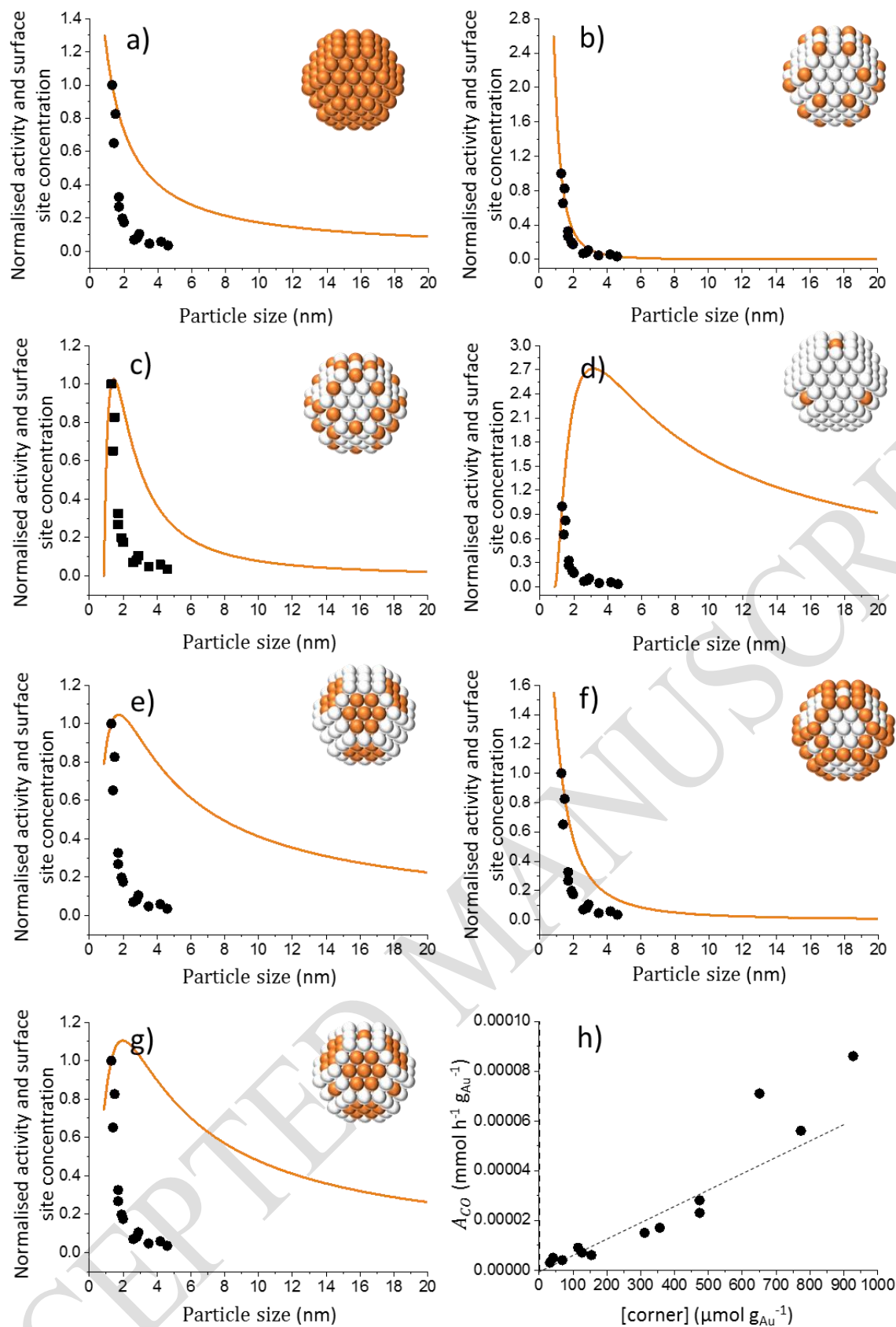

Fig.S.4. Evolution of the normalized water gas shift activity of $\mathrm{Au} / \mathrm{Al}_{2} \mathrm{O}_{3}$ catalysts (circle, [2]) and normalized surface site concentrations (orange curves) versus the particle size: a) all sites; b) corner; c) edge; d) face (100);

e) face (111); f) corner + edge and g) all faces; h) Evolution of the activity versus corner surface site concentration. Orange curves: results predicted with the model by using the particle size value $\bar{d}=1.3 \mathrm{~nm}$ for the normalization (with $\mathrm{d}_{\mathrm{Au}}=0.288 \mathrm{~nm}, \mathrm{M}_{\mathrm{Au}}=196.97 \mathrm{~g} \mathrm{~mol}^{-1}$ ). 

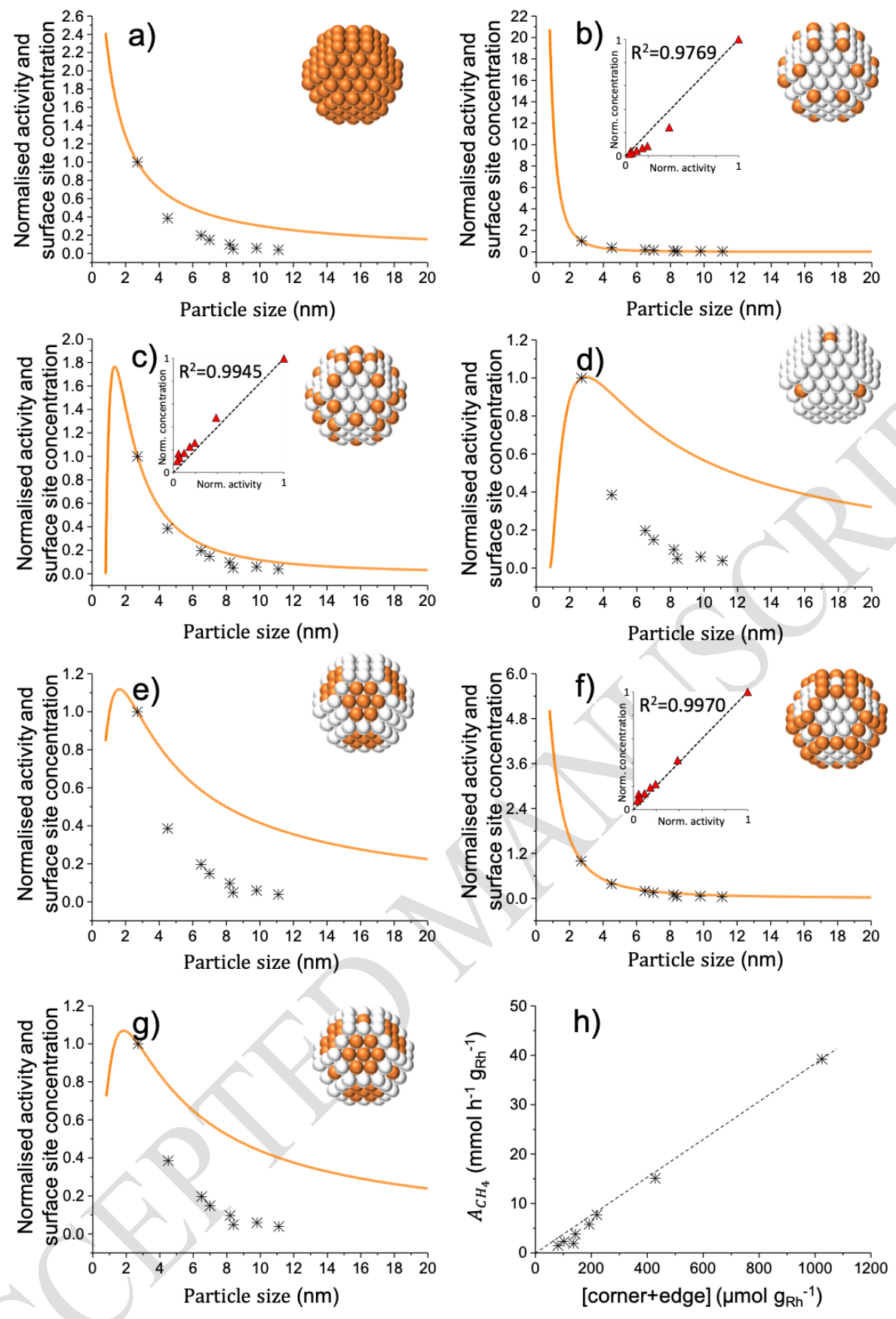

Fig.S.5. Evolution of the normalized methane steam reforming activity of Rh/ZrO 2 catalysts (cross, [3]) and normalized surface site concentrations (orange curves) versus the particle size: a) all sites; b) corner; c) edge; d) face (100); e) face (111); f) corner + edge and g) all faces; h) Evolution of the activity versus corner + edge surface site concentration. Orange curves: results predicted with the model by using the particle size value $\bar{d}=$ $2.7 \mathrm{~nm}$ for the normalization (with $\mathrm{d}_{\mathrm{Rh}}=0.269 \mathrm{~nm}, \mathrm{M}_{\mathrm{Rh}}=102.91 \mathrm{~g} \mathrm{~mol}^{-1}$ ). 

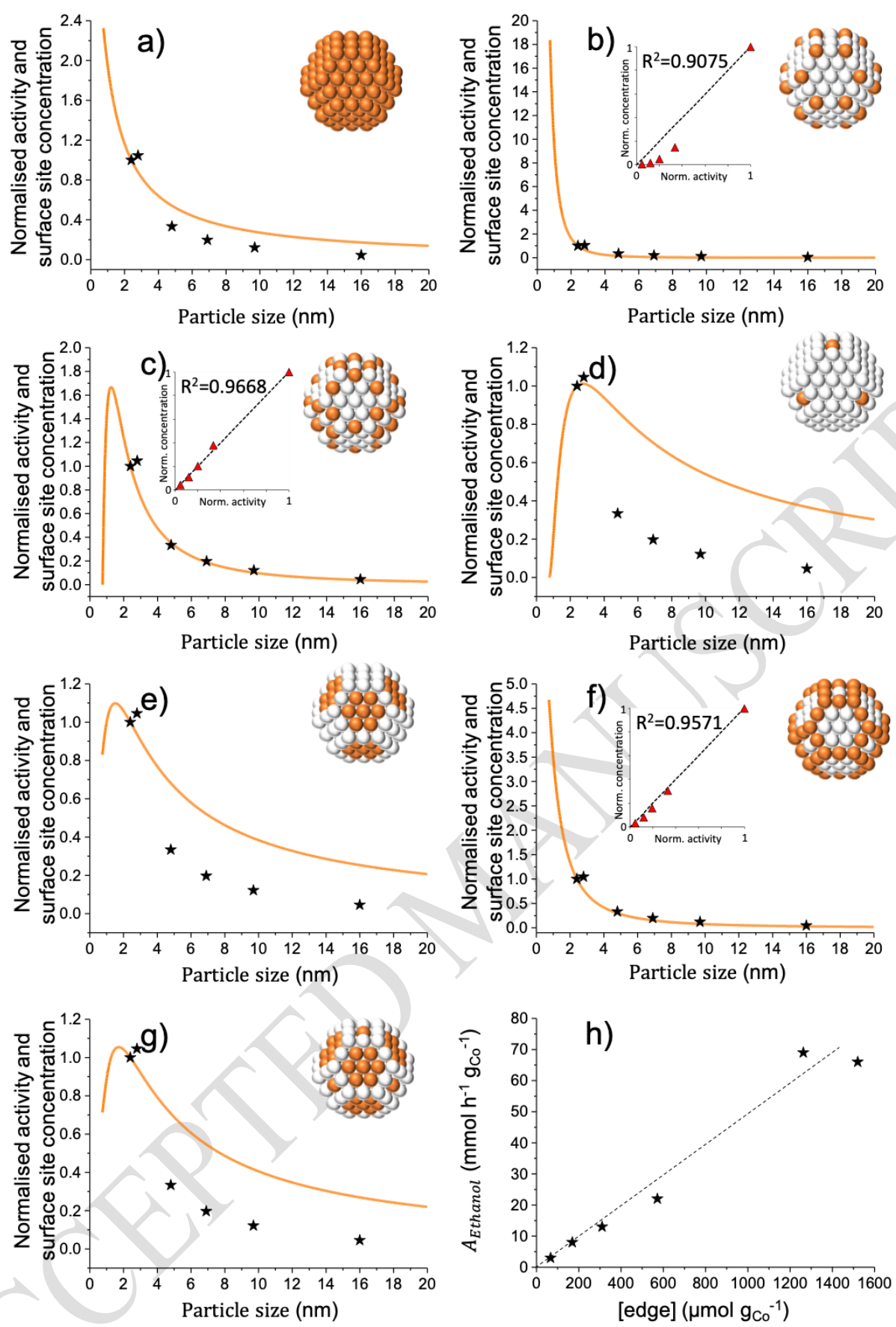

Fig.S.6. Evolution of the normalized ethanol steam reforming activity of $\mathrm{Co} / \mathrm{C}$ catalysts (star, [4]) and normalized surface site concentrations (orange curves) versus the particle size: a) all sites; b) corner; c) edge; d) face (100); e) face (111); f) corner + edge and g) all faces; h) Evolution of the activity versus edge surface site concentration. Orange curves: results predicted with the model by using the particle size value $\bar{d}=2.4 \mathrm{~nm}$ for the normalization (with $\mathrm{d}_{\mathrm{co}}=0.250 \mathrm{~nm}$ and $\mathrm{Mco}_{\mathrm{o}}=58.933 \mathrm{~g} \mathrm{~mol}^{-1}$ ).

\section{References}


[1]: R. M. Rioux, H. Song, J. D. Hoefelmeyer, P. Yang, G. A. Somorjai, High-Surface-Area Catalyst Design: Synthesis, Characterization, and Reaction Studies of Platinum Nanoparticles in Mesoporous SBA-15 Silica, J. Phys. Chem. B 109 (2005) 2192-2202.

[2]: M. Shekhar, J. Wang, W. S. Lee, W. D. Williams, S. M. Kim, E. A. Stach, J. T. Miller, W. N. Delgass, F. H. Ribeiro, Size and Support Effects for the Water-Gas Shift Catalysis over Gold Nanoparticles Supported on Model Al2O3 and TiO2, J. Am. Chem. Soc. 134 (2012) 4700-4708. [3]: G. Jones, J. G. Jakobsen, S. S. Shim, J. Kleis, M. P. Andersson, J. Rossmeisl, F. Abild-Pedersen, T. Bligaard, S. Helveg, B. Hinnemann, J. R. Rostrup-Nielsen, I. Chorkendorff, J. Sehested, J. K. Nørskov, First principles calculations and experimental insight into methane steam reforming over transition metal catalysts, J. Catal. 259 (2008) 147-160.

[4]: A. L. M. da Silva a, J. P. den Breejen, L. V. Mattos, J. H. Bitter, K. P. de Jong, F. B. Noronha, Cobalt particle size effects on catalytic performance for ethanol steam reforming - Smaller is better, J. Catal. 318 (2014) 67-74. 